\title{
COMPREHENSIVE REVIEW ON ETIOPATHOGENESIS, TREATMENT AND EMERGING THERAPIES OF BREAST CANCER
}

\author{
ARUN KUMAR* \\ Department of Pharmacology, CT Institute of Pharmaceutical Sciences, Jalandhar - 144 020, Punjab, India. \\ Email: bharmoriaarun1998@gmail.com
}

Received: 06 April 2021, Revised and Accepted: 09 June 2021

\begin{abstract}
Breast cancer (BC) appears to the most predominant form of cancer for women and the second largest factor in malignancy-associated mortality in women globally. The major predicts indicators for BC comprise lower menarche, late pregnancy, later menopause, obesity, alcohol intake, immobility, and another factor that influence the development of BC. Even though, it's rising prevalence, BC death has decreased due to screening, early diagnosis, and access to adjuvant therapies for their treatment. Chemotherapy, surgery, targeted therapy, hormone therapy, and radiation therapy are all treatments for $\mathrm{BC}$, but due to adverse side effects and several drug resistances, they are becoming largely unsuccessful. BC is a complex disorder for several different forms and classification has depended on the cell morphology and immunohistochemical evaluation focused on the deregulation gene expression of various molecular biomarkers, that is, BRCA1, BRCA2, mTOR, PI3K, RB, MDM2, TQK53, and HER2, microRNA is responsible for BC occurrences. Several in vitro, in vivo, and clinical studies are underneath assessment and many other types of research, clinical studies are promising better effectiveness against cancerous cell proliferation and related pathways involved in tumor growth and angiogenesis. Hence, in the present review, we summarized and compiled the complete information of BC about its molecular pathogenesis, biomarkers, staging system, emerging therapies, and current advancement of BC.
\end{abstract}

Keywords: Breast cancer, CDK4/6 inhibitors, Gene therapy, Mammography, PI3K/Akt/mTOR inhibitors, Nanotechnology, PARP inhibitors.

(C) 2021 The Authors. Published by Innovare Academic Sciences Pvt Ltd. This is an open access article under the CC BY license (http://creativecommons.org/ licenses/by/4.0/) DOI: http://dx.doi.org/10.22159/ajpcr.2021v14i8.41974. Journal homepage: https://innovareacademics.in/journals/index.php/ajpcr

\section{INTRODUCTION}

Breast cancer (BC) remains a prevalent malevolence or second-largest factor in malignancy-associated mortality in women globally as shown by GLOBOCAN estimates World Health Organization (WHO) 2012 responsible for $6.4 \%$ of all fatalities. Metastasis pathology is typically characterized by the spread of cancer to distinctive regions of the body that are far away in the breast or in mammary glands which identify cancer after treatment [1-7]. Besides, BC possibility since breastfeeding is also increased, primarily due to delayed childbearing [8]. In Western nations, prevalence rates are around 5 times greater than in less advanced countries or Japan [9]. Even though, it's rising prevalence, $\mathrm{BC}$ death has decreased due to screening, early diagnosis, and access to adjuvant therapies in most nations with high income in Europe or North America [10]. BC is quite prevalent in particular areas of the world, in Northern or North Europe, Mediterranean and South America, and developing countries in Africa. BC in Malaysia is among the most prevalent cancers among women, through an incidence of nearly $38.7 / 100,000$, with an average age-standardized rate (ASR) of 5410 new cases every year [11]. The American Cancer Society presents its biennial report on the most current BC data in the U.S on the number of instances and fatalities through age group in 2019, rates of occurrence and patterns by age, diagnosis stage, race/ethnicity, and molecular subtype cancer by breast until 2016 [12].

The global prevalence of women's BC, calculated by occurrence, mortality, and economic costs, is large as well as on the rise. Over 508,000 people died in 2011 worldwide due to BC, as per Global Health Figures by the WHO 2013. About 1 million of populace is predicted to be established with BC per year globally, and much more than 400,000 would die of the disease. In 2011, over 230,000 people in the US are afflicted with BC with an estimated 40,000 deaths. The cancer rate at any location will increase by $50 \%$ in 2020 , as suggested by the World Cancer Study 2000, since the genetic basis of BC or major processes concerned in tumor progress and metastases are still not well understood [13-15].
Major predict indicators for BC comprise lower menarche, late pregnancy, short or no periods breastfeeding or later menopause, obesity, alcohol intake, immobility, and hormonal replacement are also additional risks to the severity of $\mathrm{BC}$. The arrival of lumps, redness, soreness, and dimple compactness is very prominent signs and symptoms are correlated with BC (Fig. 1) [3,16].

BC is a complex disorder for several different forms and classification has depended on the cell morphology and immunohistochemical evaluation, focused on the expression of various molecular biomarkers, approximately $70 \%$ of advanced BCs are assessed as "hormone-responsive/receptor" as defined by estrogen receptor (ER), progesterone receptor (PR) expression or both, but in fact, not this hormone receptor (HR) expression tumors are truly sensitive to ER pathway regulation, with roughly $20 \%$ of $\mathrm{HR}+$ metastatic BC (MBC) or other subtypes, such as Human epidermal growth factor receptor 2 (HER2), act a part of BC growth and development (20-25\%), although Triple-negative breast cancer (TNBC) establish about 20\% BC indicating that first-line endocrine therapy is intractable [1,17-19].

BCs could be divided oriented on a four-group system their molecular structure reliant on HR expression including ER, luminal A $(\mathrm{HR}+1$ HER2-), HER2+, luminal B (HR+/HER2+), and triple-negative (TNBC, HR-/HER2-). Each subgroup has distinctive incidence potential impacts, clinical responses, disease expansion, and preferences for metastasis organ locations. HER2 receptor tyrosine kinase and Cyclindependent kinase 4 and 6 (CDK4/6) cell cycle regulators are intended for BC in HER2+ and ER+ [7,20,21]

Continual trials are focusing on finding the best molecular target treatment in BC. CDKN2A, which is located on chromosome 9 p21 or coded through tumor suppressor protein p16, is essential in the initial phases of melanoma [22].

Furthermore, for any woman with an improved life expectancy when usage systemic therapy should be addressed in the early stage diagnosis 


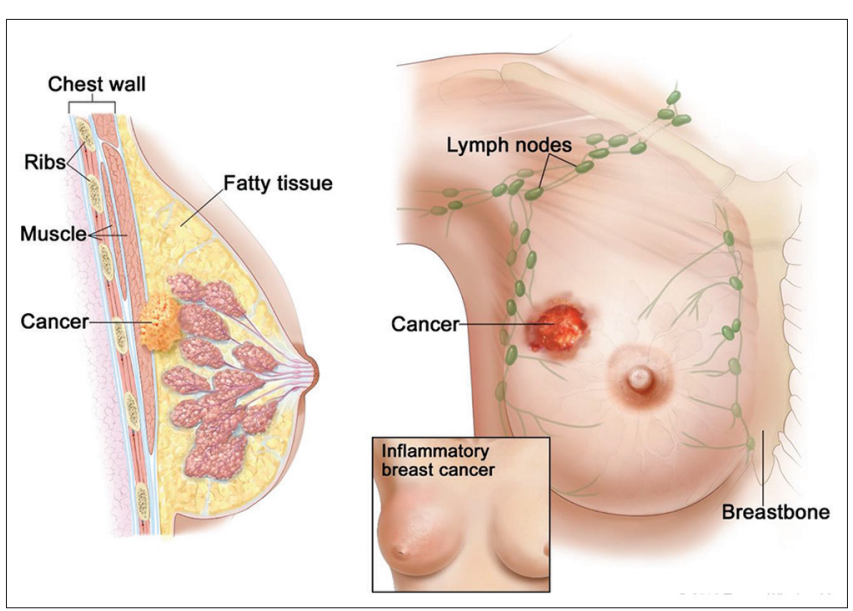

Fig. 1: Representation of breast cancer [122]

of BC. Therefore, lymph node (LN) function, tumor magnitude, and histopathological assessment are 3 primary prognostic predictors included in regular practice $[6,23]$. Simple-prolonging longevity is the main target of strategy among females by metastases BC but its effect on this objective mostly on the level of care of the person must be considered. Because metastases $\mathrm{BC}$ is usually considered an untreatable condition, treatment methods should provide an appropriate, if not desirable, the trade-off in terms of toxicity, comfort, and expense [6].

\section{MECHANISM AND PATHOGENESIS}

BC was indeed cancer that begins inside a breast cell. Many factors, as with all cancers, will raise the chances of experiencing BC. Invasive ductal carcinoma (50-75\%) is still the most prevalent form of histology of BC, accompanied through invasive lobular carcinoma (5-15\%) amid mixed ductal/lobular carcinomas. DNA disruption or genetic mutations may be testable associated with estrogen susceptibility to BC. Few people have DNA abnormalities or genes such as BRCA1, BRCA2, and P53. Usually, the immune response takes out cancer cells and kills compromised DNA cancer cells. The lack of such successful immune protection or monitoring will result in BC. There are some growth factor signals or other mediators communicating with stromal or epithelial cells. These diseases may also affect BC $[24,25]$.

$\mathrm{BC}$ is progressively infiltrated and spreading across the local LNs, blood circulation, and even together. BC that has spread to other organs can normally influence the lungs liver, bone, brain, and skin. The bulk for skin malignancies happen at its breast operation base, scalp metastases are normal as well. The two key genomic factors were established throughout the pathogenicity of BC. The ERs of BC progression exists in alpha $(\alpha)$ and beta $(\beta)$. Such receptors are presented by different tissues of the breast, ovary, or endometrium stating ER $\alpha$. Whereas liver, brain, lungs, and few other organs exhibiting ER $\beta$. The function of ER $\beta$ in carcinogenesis is unclear, although ER $\alpha$ protein also clearly made its impact. The HRs are ER and PR are existing in BCs facilitate duplication and partition of the DNA when the hormones attach to a receptor. Moreover, the abnormal stimulation of estrogen contributes to the activation of oncogenic growth pathways, clearly linked to PR or as a cue for induction of ER $\alpha$ signaling in BC cells [15,26-28].

When estrogen enters the cell, the ER is binding or the complex relocates into the center or produces transcription proteins that trigger genetic alterations. Due to a proliferative characteristic of estrogen, cell activation of patients possessing significant amounts of such receptors intracellularly can have detrimental effects. The function of estrogen in the growth and production of BC. As a result, the two main theories seek to discuss tumorigenic results of estrogen (a) Genotoxic impact of estrogen metabolites by radical (initiator) formation and (b) the hormonal characteristics and pre-malignant cells of estrogen-inducing cancer spread (promoter) $[27,28]$.
The lacking of HR or HER2 expression is deemed a subclass in TNBC. This includes roughly $15 \%$ of BCs known as molecular pathways for breast cells that don't prompt ER, PR, or ERBB2. The one to four periods in cancer cell regulation are a major risk of distinct decreases in tumor cell diagnosis over an initial 3-5 years, according to detailed cellular pathogenesis of TNBC. Stage IV BC suggests some marginal BC threat metastatic progression, while for subtypes of HR+, ERBB2+, and triple-negative, Stage IV indicates a maximum cumulative lifespan of nearly 5 years. Step I and separate biologically submerged LN of BCs or individual breast tumor cells tend to be $<2 \mathrm{~cm}$, the precise survival of 5-year BC almost $94 \%$ or a minimum of $85 \%$ are HR+, ERBB2+ [25].

Tumor factors affecting only $1 \%$ of tumor cells which is distinguished via $\mathrm{HR}+7$ via ER or PRs existence. Therefore, sole systemic therapy usage in case of ER-positive or PR-positive may trigger BC cells by reduces ER signaling regulators. Most breast malignancies are caused by epithelial cells and are also carcinomas. The HER2, HER2/neu, and ErbB2 is another cell receptor, its existence leads to a weaker prediction of any given cancer phase. HER2 receptors are overexpressed in around $20 \%$ of BC patients or overexpression/extension of ErbB2/positive amplified gene in patients have benefits through ErbB2 targeted therapy comprising anti-ErbB2 antibodies (trastuzumab and epratuzumab) and small molecule inhibitors of tyrosine kinase (lapatinib and neratinib). The diagnosis came after multiple cycles or years of early identification and treatment. Medicines that oppose such receptors benefitted to cure receptor tumors as well $[1,26,29,30]$.

In comparison, proliferative breast disease has a greater probability of BC. Proliferative breasts without atypia, such as typical ducts, are hyperplasia, intraductal papilloma, fibroadenomas, and sclerosing adenosis, are just marginally more likely than average to grow $\mathrm{BC}$, around 1.5-2 periods. Uncharacteristic, ductal, or lobular hyperplasia, typically detected accidentally during mammography screening, creates considerably more of a threat for BC. The probability of emerging cancer in females with atypia is around 4.3 times higher in contrast with both the regular populace [31]

\section{BIOMARKERS OF BREAST CANCER}

$\mathrm{BC}$ 's genetic effects, or the key pathways implicated in tumor expansion and metastasis, are only partially known. BC historically was already divided into four distinct molecular subgroups/subtypes depending on their existence and lack of three receptors initiate on cancer cells. These subgroups/subtypes include - luminal A (HR+/HER2-), HER2+, luminal B (HR+/HER2+), or triple-negative (TNBC, HR-/HER2-). Each subgroup has various risk factors for metastatic occurrence, clinical activity, or disease development. HR (ER and PR) are encouraging for luminal BC. Moreover, Luminal BCs remain far too heterogeneous relative to basal cancers despite gene regulation, mutant extent, replicate sequence shifts, or patient results or are sectioned into luminal A (HR+/HER2-) that articulate ER or PR with low P53 point mutations, signifies $50-60 \%$ of BC or luminal B subtypes (HR+/HER2+) present an improved gene expression are ER+, PR+/-, HER2+/-, EGFR+ and more established through his proficiency rate (proliferation marker) of Ki67 P53 or HER2 mutation. Since luminal cancer has a high prevalence of PIK3CA mutation (Gene encoding p110 $\alpha$ catalytic subunit of phosphatidylinositol 3-kinase [PI3K]). Positive BCs of the HR prompt ER/PRs or account for about $60 \%$ of all cases of BC. Nearby $20 \%$ of BC events are over-expressed with the HER2/neu. whereas only $20 \%$ are negative $\mathrm{BC}$ cases for $\mathrm{ER}, \mathrm{PR}$, and HER2/neu, often recognized as TNBC $[4,7,32]$.

TNBC consist of six distinct subtypes having their carriers, clinical phenotypes, or molecular profiling includes basal-such as 1 and 2, immunomodulatory, mesenchymal, mesenchyme, and luminous androgen receptor. Normal genome changes in TNBC contribute to dysregulated cycle progression or induction of apoptosis, such as lack of TP53, RB1, BRCA1, or PTEN, and also to alterations in the operation of cyclin-dependent kinases (CCNE1, CCND1, CDK4, CDK6) and PI3K, 
namely PIK3CA mutations, resulting in a mutation or lack of TP53 occur $68 \%$ of TNBCs or $80 \%$ basal-like BCs. The word "BRCAness" refers to TNBC genotypes that have BRCAs but are identical to a clinical and biological phenotype such as BRCA deficiencies. Mechanisms for gene duplication of TNBCs without any germ-line BRCA1/2 mutations, such as promoter methylation, somatic BRCA mutations, or transformed articulation of other genes including TP53, PALB2, ATM, and HORMAD1 are likely to result in alternatives [33].

Additionally, transforming growth factor $\beta$ (TGF- $\beta$ ) facilitates musculoaponeurotic fibrosarcoma overexpression of oncogene family protein $\mathrm{K}$ (MAFK) through activate EMT, accelerate tumor development or in vivo invasion. The EMT system normalized through TGF- $\beta / \mathrm{Smad}$ signaling through includes WAVE3, a WASP/WAVE family actin-binding protein TGF- $\beta$ induced EMT phenotype was disrupted in TNBC cells by deletion of WAVE3 function, for example, The CXCL14 and CXCL12 chemokine's are encoded in two highly overexpressed genes, which link cancer cells with CXCR4 and aid in their migration and invasion. CXcr4 receptor triggered through CXCL12 and ANGPTL2 ligand concluded in persuade MLK3 and Erk1/2 signaling and facilitate intravasation leading in a certain production of lung and bone metastasis. At the same time, transendothelial migrations or the penetration of cells with BC in the vasculature is increasingly evident, as are metastasis suppressors such as TP63, LIFR, LOXL4, FOXF2, SSBP1, RAB1B, and TIEG1 [32]. More example of PI3K/Akt/mammalian or mechanistic target of rapamycin (mTOR) pathway performs its important part in cellular functions, from cell expansion to differentiation to uptake, its initiation even connected to HER2 and its family of receptors. It exhibits the PI3K/Akt/mTOR pathway undesirably triggered in $\mathrm{BC}$, making agents that prevent also PI3K, Akt, or mTOR for chemotherapy [34].

HER2 (ErbB2/neu) is an affiliate of a HER1, HER3 (ERbB3), or HER4 (ErbB4) network of transmembrane tyrosine kinase receptors. HER2 over-expression causes proliferation through affecting the roles of proteins that control cell cycle progression or apoptosis. HER2+ BC increased HER2/ERBB2 oncogene expression and activation, contributes to the enabling of a PI3K and serine/threonine kinase Akt signal cascades or anti-HER2 therapies may be used to cure it. Inactivation of p27 expression often comprises downstream results of the PI3K-acct pathway (a Cdk2 inhibitor). Trastuzumab raises nuclear and cytosolic p27 levels, which contributes to cell cycle detention. Basal-like BC lacks HR/HER2, signifies $10-20 \%$ of BC, or has significant P53 mutations in conjunction with loss of $\mathrm{Rb} 1$, which is why it is sometimes termed TNBC. Maximum people in BC $(84 \%)$ have $\mathrm{HR}+$ diseases, including $71 \%$ HR+/HER- (luminal A) or $12 \% \mathrm{HR}+/ \mathrm{HER} 2+$ (luminal B). HER2+ nor HR- are just $5 \%$ of BC patients. TNBC accounts for more than a fifth of the patient population $(12 \%)[7,32,35]$.

The factor fibroblasts termed cancer-associated fibroblasts exude some soluble factors include chemokine's or growth factors that alter tumor stroma or result in increased tumorigenesis or invasion. Moreover, dendritic cells (DC) perform a significant role in inducing anti-tumor reaction due to their capacity to exist in two ways antigens to $\mathrm{CD} 4+$ or CD8+ $\mathrm{T}$ cells but also activate neoplastic cells, tumorrelated cytokines such as vascular endothelial growth factor (VEGF), IL-10 or prostaglandin E2, and could lead DC evolution to a monitoring phenotype that prevents T-cell proliferation. In the case of tumorassociated macrophages (TAMs) constitute a vital cellular component with $\mathrm{BC}$ that shows a typical phenotype engineered to encourage the development of the tumors or angiogenesis, tissue remodeling as well as suppressing adaptive immunity. TAM develops multiple tumors such as VEGF, cytokines, and enzymes to promote invasion, angiogenesis, and metastasis. The majority of TAM belongs with M2 phenotype allowing cancer cells may persist and spread through IL-10, CCL2, CCL17, and CCL2 2 secretions and TGF- $\beta$ Lymphocytes. Tumorinfiltrating lymphocytes (TILs) are T-cells is possible to categorize in the CD4+ helper cells, T reg by a CD4+, CD25+, FOXP3+ phenotype or effector cells including natural killer cells or CD8+ T cells [36].
Cancers with a significant level of pre-existing immunity were identified as 'inflamed' cancer form or are distinguished by the occurrence of TIL, programmed death-ligand 1 (PD-L1) as well as CD8 T-cells of tumors and immune cells with the manifestation of a solid interferon-gamma cytolytic T-cell cross-low expression of PD-L1 typically partially invaded by TILs forms of tumors which are incapable of raising a specific antitumor immune reaction with a predictive marker of CIT, yet the ability to transform through an inflamed phenotype with chemotherapy or a presumed mixture of CIT agents [37].

\section{EPIDEMIOLOGY}

BC appears to the most predominant form of cancer for women, with $23 \%$ of all women's cancers worldwide reported. More than 1.7 million females are tested for BC diagnosis before 2020 or trends in predominantly developed countries rise by $26 \%$. Any social causes, including smoking, tobacco, obesity, or other hormonal threat measures include things such as early menarche, retarded parity, and decreased breastfeeding [15].

Asian nations have seen an increase in BC occurrence and prevalence. In 2007 there had been approximately 8,123 (44.6\%) male or 10,097 (55.4\%) female cancer cases reported in Malaysia. As per the 2012 study through International Organization for Research in Cancer (GLOBOCAN) the ASR with BC to Malaysia was reported at 38,7/10.0000 individuals in 2012 to 5, 410 cases testified or the National Cancer Registry of Malaysia in 2007 exposed a BC ASR in Malaysia was also disclosed to 29.1 of 100000 women respectively. This means that about 1 in 35 women in the republic in their lifespan will experience BC. The BC frequency marginally grew about $0.3 \%$ annually during the last 5-year period (2012-2016), primarily due to the increased concentrations of local level or HR-positive disease. Instead, the rates of mortality from BC are starting to weaken, declining by $40 \%$ between 1989 and 2017 or transforming to $375,900 \mathrm{BC}$ mortalities prevented. Over the last 5 years (2013-17), Hispanics (2.1\%/annum), blacks (1.5\%), whites (1.0\%), and Asians/pacific $(0.8 \%)$ death rate are dropped but remained stable among Americans/Alaska indigenous groups [11,12].

Upwards of 266,000 fresh instances of invasive BC, including almost 64,000 additional reports of non-invasive BC between U.S. women, are projected to be reported in 2018 as well as around 2,500 fresh incidents of invasive BC in males are diagnosed in 2018 and also be more than 40,000 US women are predicted to die with BC. Although it is projected that 268,600 separate incidents of invasive BC among females and 2,670 new cases in men will be reported in 2019. Furthermore, appraised that 48,100 individuals have ductal carcinoma in situ (DCIS). In 2019, 41,760 women and 500 men are estimated to die from BC. Indeed, with the distinction of lung cancer, the death rate for women in the U.S is higher than among all cancers $[3,38]$. Largely, there are few recorded $\mathrm{BC}$ instances in Asian nations, but they're now seeing a rise in diagnosis. In some studies, in Asian nations virtually each one of 19 females has concerns involving BC incidence and prevalence [23].

In India, almost 100,000 females with cancer have been identified per year with elevated raises in urban areas, and a growing number of incidents in all parts of India, close 131,000, with raises of $0.5-2 \%$ each year and above in all ages of 45 in younger females and half of the Indians suffering from BC are premenopausal states in 50-53 years age [13].

In 2026, the accumulative number among BC patients across the U.S is expected to exceed 4 million. BC affects approximately 11,000 American women under 40 years of age. Young women were quite inclined to experience indicative $\mathrm{BC}$ as a result of the relative reduction in prevention and diagnosis. Every year, almost 70,000 Americans on 70 years of age raise their BC chance. BC was widespread in nearly $19.3 / 100,000$ all people in East Africa, or the BC proportion is very high in developed countries (except Japan), at 80,100,000 women. As is the case in Pakistan, 50.1/100,000 women are present in BC every year [39]. An estimated 2.1 million new $\mathrm{BC}$ women were reported in 
2018. Moreover, $62,6679 \mathrm{BC}$ women died. The worldwide commonness of BC has increased by $3.1 \%$ annually, starting from 641,000 cases in 1980 , to $>1.6$ million in 2010, the world's largest occurrence differs, with greater probability in high-income nations $(92 / 100,000$ in North America) in contrast with that in low-income nations $(27 / 100,000$ in Middle Africa and East Asia) [30].

$\mathrm{BC}$ had become a leading consequence of mortality for Arabic women during their younger years. The same age rates of incidence for Lebanon in 1998 were $46.7 / 100,000,69 / 100,000$ in 2004 , and $84 / 100,000$ in 2007. ASRs of age-specific standardized incidences mostly seen in groups younger than 50 years are $153 / 100,000$ in $1998,194 / 100,000$ in 2004, and 286/100,000 in 2007, concerning 42.5/100,000 of BC occurrences in the U.S. The average age of $\mathrm{BC}$ with $49.1 \%$ cases under 50 years age in Lebanon is equivalent to 63 years for developed nations [13].

\section{TYPES OF BREAST CANCER}

Multiple genetic variations that disrupt the body's specific role have been identified to induce or detect many kinds of BC (Fig. 2).

\section{Invasive Breast Cancer}

Invasive $\mathrm{BC}$ is a very common term coined to cancer that will progress beyond invasive ductal BC (ducts) or invasive lobular BC (lobules). This will get somewhat divided through its histopathology, that is, tubular, mucinous, medullary, and papillary breast tumors were unusual BC subsets. This tumor may penetrate to adjacent fatty and connective breast tissues by breaking the membranes in glands and ducts [16,40-43].

\section{Noninvasive Breast Cancer}

BC is graded as non-invasive (in situ) or invasive cancer. In situ carcinoma is categorized through expansion insides ducts without any infiltration of membrane or the stroma ducts. In situ carcinoma is further sectioned into DCIS and lobular carcinoma in situ (LCIS). DCIS involves the situation wherein unequal cells substitute regular breast epithelial cells and may significantly spread the ducts and lobule. Moreover, DCIS is a variety of noninvasive BC in which their abnormal cells had not built up within its cell surface which it initiated. Since the risk of in situ ductal carcinoma developing into invasive cancer is high, it is crucial to protect the patient from developing invasive cancer at an early stage $[3,16,40-45]$.

\section{Lobular Carcinoma In Situ}

Lobular neoplasia occurs if there an alteration inside their lobule's cell lining (produce breast milk), which suggests that an elevated risk indicates that $\mathrm{BC}$ emerging in the potential/later [40]. LCIS is distinctively multicentric and bilateral and measured as a raised marker probability of a patient emerging invasive carcinoma [42-45].

\section{Paget's disease}

Paget disease is a unique form of ductal carcinoma that affects older people. It starts with a common intraductal cancer that originates from the breast's major excretory ducts or expands intraepithelial to cover the nipple and areola tissue. Affected skin is also cracked, ulcerated, or oozed. Inflammatory hyperemia and edema are around and bacterial infections often occur [43].

The diagnosis of Paget's disease by shaven biopsy, surface biopsy, punch biopsy, and wedge biopsy, whereas women with Paget's nipple disease have lower cancer indications about 1\% [42].

Paget disease causes $<3 \%$ of certain BC occurrences. The cells of Paget appear dramatically dissimilar into regular cells or may divide readily. Around half of the cells are positive for ERs and PRs or the rest will positive for HER2 protein [3]

\section{Inflammatory Breast Cancer}

Invasive $\mathrm{BC}$ was an unusual category in inflammatory $\mathrm{BC}$ that representing $1-5 \%$ with all most BCs. From its signs, diagnosis, or treatment, inflammatory $\mathrm{BC}$ varies from several other varieties of BC. Typical inflammatory BC is a kind of inflammation, swelling, red skin color, and pitting or breast thickening, affected by obstruction of lymphatic lymph cells or channels across the breast skin. However, inflammatory BC could not identify through mammograms $[3,42,46]$.

\section{Triple-negative Breast Cancer}

Triple-negative BC becomes an advanced invasive BC form that's still described by ER-negative, PR-negative, or HER2-negative for about $20 \%$ among all BCs. Triple-negative BC is far increasingly frequent in women below 40 age of with BRCA1 gene mutations or African and Americans are extra obvious. In premenopausal women, such BC varieties become crucial and are usually found in $10-15 \%$ of reports in white women. The most typical histology observed in TNBC is the infiltration of ductal carcinoma, while medullary carcinoma is still usually triple-negative BC for a specific histological subgroup [46,47].

\section{BREAST CANCER STAGES}

The initial stage, stage 0 , and noninvasive $\mathrm{BC}$ notify that the disorder has no evidence of spreading to LNs.

\section{Stage I BC}

Cancer measures $2 \mathrm{~cm}$ in size or less but has not progressed.

\section{Stage IIA BC}

Tumor $<2 \mathrm{~cm}$, with underarm LN association $>2$ and smaller than $5 \mathrm{~cm}$, if not LN immersion.

\section{Stage IIB BC}

Tumor bigger than $5 \mathrm{~cm}$, excluding the $\mathrm{LN}$ intervention under the arm or higher than 2 and smaller than $5 \mathrm{~cm}$, with LN interference.

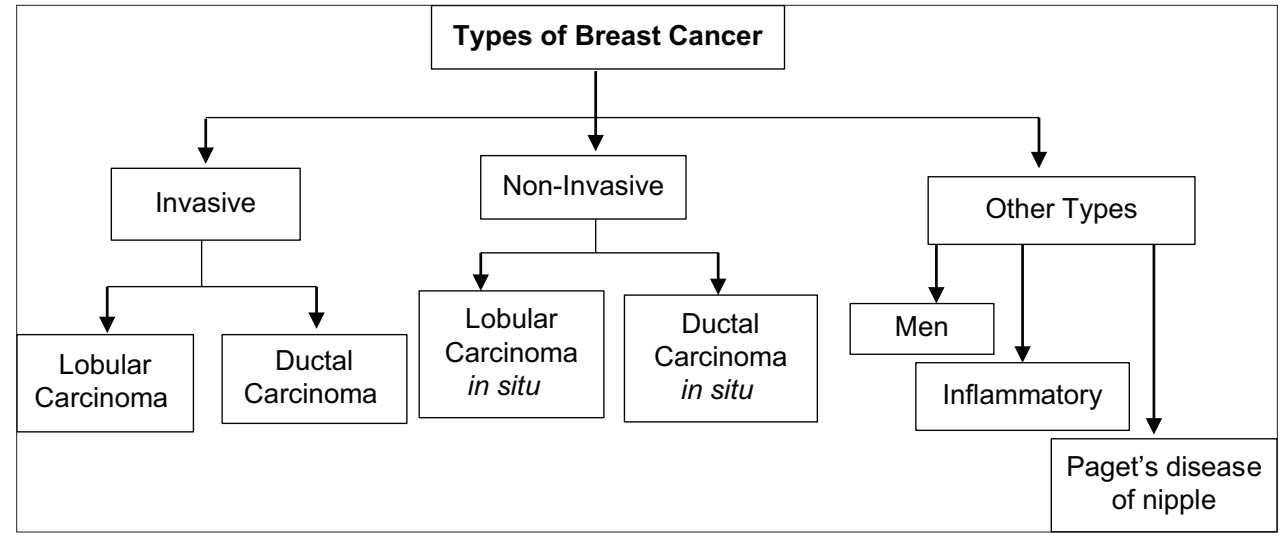

Fig. 2: Types of breast cancer [123] 


\section{Stage IIIA BC}

Tumor superior to $5 \mathrm{~cm}$ means it may proliferate to the nearby breastbone in under the arm LNs.

\section{Stage IIIB BC}

Any size of cancer progressed to the skin or chest wall.

\section{Stage IIIC BC}

Any size of the tumor has proliferated further and comprises other LNs.

\section{Stage IV MBC}

Irrespective size of the tumor has been progressed to sites significantly apart from the breast include bones, lungs, liver, brain, and distant LNs [44].

\section{TNM staging system of Breast Cancer}

TNM staging system was employed to identify the tumor size and position utilizing " $\mathrm{T}$ " plus letters or numbers (0-4). The scale of the tumor size is estimated in centimeters $(\mathrm{cm})$. The thickness of a regular pen and pencil is approximately equal to a centimeter. The stage can also be separated into equal classes which help to better explain the tumor. Details on the particular tumor stage in the following.

\section{A tumor (T)}

TX - The tumor cannot be determined.

T0 (T plus zero) - No symptoms of BC.

This-referred to carcinoma in situ allocated into 2 different forms such as Tis (DCIS) and Tis (Paget's).

T1 - The breast tumor has a size of $20 \mathrm{~mm}$ or less on its broadest site. It's just under one inch. This stage then is divided into 4 sub-stages according to tumor size (Fig. 3):

T1 mi smaller and $1 \mathrm{~mm}$.

$\mathrm{T} 1 \mathrm{a}$ is $>1 \mathrm{~mm}$ but $5 \mathrm{~mm}$ or lesser.

T1b larger than $5 \mathrm{~mm}$ but $10 \mathrm{~mm}$ or littler.

T1c higher than $10 \mathrm{~mm}$ but $20 \mathrm{~mm}$ or minor

T2 - Tumor is higher than $20 \mathrm{~mm}$ but not more than $50 \mathrm{~mm}$

T3 - Tumor is higher than $50 \mathrm{~mm}$.

T4 - The tumor is in 1 of these classes:

$\mathrm{T} 4 \mathrm{a}$ indicates that a tumor is developed into the walls of a chest.

$\mathrm{T} 4 \mathrm{~b}$ when there is a skin tumor.

T4c tumor grows in the chest or skin wall.

T4d inflammatory BC.

\section{Node (N)}

The means of "N" within their TNM staging system support LNs. The role of such tiny, bean-formed organs helps to prevent infection. LNs close to which melanoma has begun is termed regional LNs.

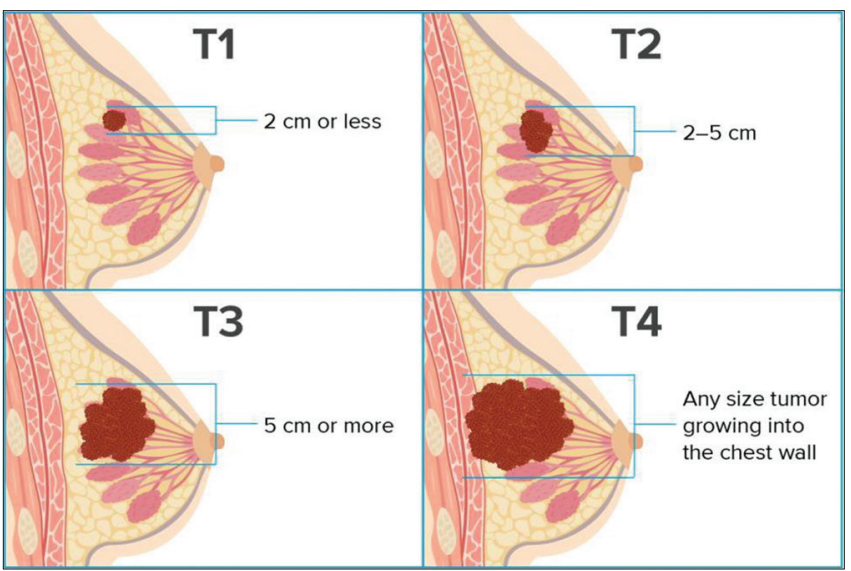

Fig. 3: Stages are based on tumor size [124]
NX - No assessment of LN

N0 - No cancer testified in LN and just include the site of cancer $<0.2 \mathrm{~mm}$. N1 - Cancer reached 1-3 axillary LNs as well as inner mammary LNs. Unless the $\mathrm{LN}$ cancer is more than $0.2 \mathrm{~mm}$ and $2 \mathrm{~mm}$ or less, mentioned as "Micro metastatic" (N1mi)

N2 - Cancer proliferates to 4-9 axillary LNs and maybe in interior mammary LNs, then not the axillary LNs.

N3 - Cancer progresses of 10 and above axillary LNs or interior mammary LNs or to the lymphatic nodes situated beneath their clavicle and collarbone. Cancer distributed across the clavicle over the LNs known as the supraclavicular LNs is often referred to as N3.

\section{Metastasis (M)}

The "M" within the TNM system explains if cancers may proliferate to other body parts named "Distant Metastasis." The initial onset or locally advanced cancer was no longer measured.

MX - Distant proliferation can't be assessed.

M0 - Distant metastases are not apparent.

M0 (+) - The confirmation of distant metastases is not clinical or radiographic. Even so, tumor cells within blood, bone marrow, and further LNs were microscopically detected, that is, not $>0.2 \mathrm{~mm}$.

M1 - Metastases to another body part have been seen, which means that BC cells develop in another organ $[48,49]$.

\section{RISK FACTORS}

\section{Age}

A study documented fewer than 10 confirmed cases of 100,000 women under age 25 or up to 100 times as young as 45 years. This suggests that $\mathrm{BC}$ pathogenesis is implicated in the reproductive hormones released in ovaries and adrenal glands because cancers that do not respond to hormones display significant occurrence changes during the woman's reproductive cycle. Furthermore, menarche and menopause ages are considered to lead to the period revelation to carcinogenic impacts of gonadal (sex) hormone [50]. BC is more common as people become older, and the lifetime risk can be as high as 1 in 8 women in populations that seem to have a longer lifespan in those high-resource settings. The effect of age mostly on the BC manifestation in LMICs is quite well established but is more significant with increased life expectancy [51]

\section{Family history}

The $\mathrm{BC}$ risk is greater in females who had the diagnosis with a near family member (mother, sister, or daughter). This is believed to be due to a variety of influences, namely both hereditary and atmospheric conditions. The rise in incidence is extremely high when $\mathrm{BC}$ has formed relatively earlier than the 50 age. As per the American Cancer Society, almost $80 \%$ of BC women have no family background with the condition. In reality, before initial diagnosis, most people with $\mathrm{BC}$ are unaware that they were in the positive zone $[51,52]$.

\section{Gender}

The most serious consequence of BC is having in a woman. Since women get a larger breast size than men, the condition is 100 times greater frequent to women than in men. Estrogen, a woman hormone, also facilitates cancer cell development. Male's patients make up just less than $1 \%$ of $\mathrm{BC}$. Even so, the variations are believed to be hormonal, male $\mathrm{BC}$ has also been found to articulate ER, PR, or androgen receptors, and men with Klinefelter syndrome were known to include a far higher chance for contracting BC $[50,52]$.

\section{Genetic factor}

$\mathrm{BC}$ was mostly caused by a medical or family experience with the disease as well as hereditary abnormalities inherited from BC. Only $5-6 \%$ of BCs have been deemed to be genetic, as a potential cause for $\mathrm{BC}$, genetic factors continue to play a restricted and yet significant role. An assessed $80 \%$ of genetic BC is represented by BRCA- 1 or BRCA- 2 . BRCA-1 or BRCA-2 positive women get a lifelong chance of emerging BC with $50-85 \%$ or ovarian cancer with $15-65 \%$. They are covered through numerous mechanisms or proteins before apoptosis. Such 
mechanisms also include PI3K/AKT pathway and the RAS/MEK/ERK pathway. At the period with cell apoptosis, the PTEN protein is usually capable of inhibiting the PI3K/AKT pathway. In certain circumstances, PTEN protein mutations exist and leading to unregulated tumorigenesis $[53,54]$.

\section{Other genetic factors}

ATM

The ATM gene typically encourages the regeneration of damaged DNA. Inheriting two deficient variants of a gene origins condition ataxiatelangiectasia. In certain populations, inheriting a defective variant of an allele is also attributed to an increased chance of experiencing BC.

\section{TP53}

The TP53 allele helps to minimize the development of damaged DNA cells. Hereditary mutations of this gene may induce Li-Fraumeni syndrome. BC, as well as other conditions such as leukemia, brain tumors, and sarcomas, is more frequent in patients with this disease.

\section{CHEK2}

A gene that usually assists with DNA synthesis seems to be the CHEK2 gene. Mutation in the CHEK2 gene increases the likelihood of BC.

\section{PTEN}

Normally, the PTEN gene aids in cell division regulation. Inherited variations in this allele can cause Cowden syndrome, a genetic condition that raises the likelihood of cancer and benign (non-cancerous) tumors in the breasts, or deformities in the digestive tract, thyroid, uterus, and ovaries.

\section{CDH1}

Inherited genetic alterations trigger genetic differential gastric cancer, a condition where a severe case of stomach cancer occurs in individuals. Women that have defects in such allele are more likely to get invasive lobular BC.

\section{STK11}

In this sequence, mutations may contribute to Peutz-Jeghers syndrome. Pigmented patches around the lips and noses, polyps (abnormal growths) in the urinary or digestive tracts, and greater prevalence of some cancers, such as BC, are all symptoms of this condition.

\section{PALB2}

A PALB2 gene which associates with protein produced through the BRCA2 gene. BC risk can be raised by genetic mutations [39]

\section{Lifestyle-related risk factors}

Obesity, alcohol, tobacco smoking, not breastfeeding, low physical activity, precise nutritional habits (high intake of fat, low intakes of fiber, fruits, or vegetables).

\section{Hormone replacement therapy}

Combined hormone therapy (HT) bioidentical HT estrogen therapy (ET), prescribed diethylstilbestrol, breast implants [47]

\section{Environmental factors}

Exposure to ionizing radiation, exposure to carcinogens (substances that cause cancer).

\section{Infections}

Inflammatory lesions, benign fibrocystic lesions, benign breast diseases, proliferative breast disorder, carcinoma of the breast.

\section{Other factors}

Premature age at menarche, mature age at menopause, late age pregnancy, exposure to ionizing radiation, abortion, breast augmentation, low intake of phytoestrogens [50-53]

\section{SIGN AND SYMPTOMS OF BREAST CANCER}

The sign and symptoms of breast cancer are (Fig. 4)

- Lump.

- Change in breast shape or size.

- Breast and nipple pain

- Nipple retraction.

- Swelling in the entire portion of the breast.

- Skin irritation and dimpling.

- Nipple retraction.

- Red, dry, peeling, scaling, flaking, pitting, or thickened skin of nipple or breast.

- Nipple ejection.

- Bloody secretion within the breast.

- Swollen LNs [55-58].

\section{EMERGING THERAPIES OF BREAST CANCER}

\section{CDK4/6 inhibitors}

Linking to D-type cyclins stimulates CDK4/6 primary on a G1 phase. In the G1 phase, CDK specifically regulates the retinoblastoma sensitivity gene product $(\mathrm{pRb})$, which facilitates G1 arrest by sequestering E2FDP transcriptional factors and then transcription of S-phase-required genes. Cyclin D1 and phosphorylated Rb for adaptation, and $\mathrm{p} 16$ for tolerance, can be predictive variables for CDK4/6 inhibitors. CCND1 (cyclin D1) extension (29-58\%), CDK4 (14-25\%), and CDK6 extension (14-25\%), p16 deficit (49\%), and TP53 alteration (12-84\%) are all typical deregulations in $\mathrm{BC}[59,60]$. The most attention has been paid to CDK4/6 inhibitors (Palbociclib, Ribociclib, and Abemaciclib). The intermittent association of CDK4/6 with cyclin D1 constraints cell cycle progression. Amplification of cyclin D1 and CDK4 was observed in nearly 29 or $14 \%$ of HR+/HER2 BC patients. Crucially, except although tumors establish hormonal tolerance, they often focus on CDK4/6-cyclin D1 for propagation. As a result, following therapy by HT variability or a CDK4/ 6 receptor, HR+/HER2 BC showed more marked G1-S cell cycle arrest CDK4/6 inhibitors obstruct the retinoblastoma protein phosphorylation of causing E2F-response genes to down regulate and mediate G1-S arrest. The transcription feature is still dephosphorylated by them. M1 (forkhead box protein) is a protein that inhibits cell proliferation $[61,62]$.

\section{Palbociclib}

Palbociclib is a CDK4/6 inhibitor that is taken orally and is reversible. Palbociclib can isolate CDK4/6-cyclin D1 clusters, blocking $\mathrm{Rb}$ phosphorylation and preventing E2F1 entry, leading to G1 step arrest and tumor growth suppression. Palbociclib has a half-life of over $29 \mathrm{~h}$ in the body. The liver is the major metabolic site, where it is metabolized through SULT2A1 and CYP3A, and the feces (74.1\%) and kidneys are also the key excretion routes $(17.5 \%)[63,64]$.

\section{Ribociclib}

Ribociclib is an exceedingly orally bioavailable selective CDK4/6 inhibitor. In preclinical experiments, ribociclib prompted tumor

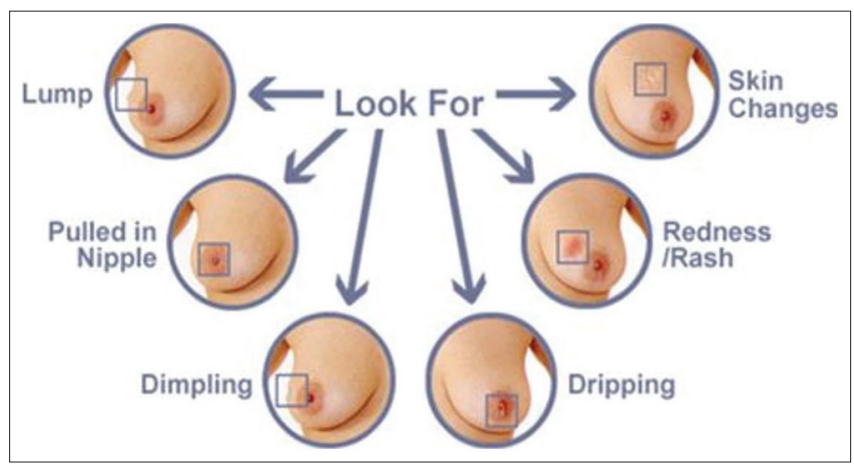

Fig. 4: Sign and symptoms of breast cancer [125] 
growth inhibition and cell cycle arrest in dose-dependently of multiple $\mathrm{Rb}$-proficient cell lines. In such some xenografts tumor models, such as PIK3CA-mutant BC, NRAS and BRAF-mutant melanoma, and neuroblastoma, the antitumor function has been reported $[59,65]$.

\section{Abemaciclib}

Abemaciclib is a CDK inhibitor utilized in combination with antiestrogens to treat postmenopausal women diagnosed with MBC. It has possible anticancer properties which regulate the CDK4 (cyclin D1) and CDK6 (cyclin D3) cell cycle pathways. Abemaciclib prevents retinoblastoma $(\mathrm{Rb})$ protein phosphorylation of initial G1 by directly inhibiting CDK4/6. Rb phosphorylation blockade prohibits CDK-mediated G1-S phase transitions, halting the cell cycle within the G1 phase, blocking DNA replication, or slowing cancer cell proliferation $[66,67]$.

\section{Anti-HER2-targets agents}

Intracellular and extracellular observations of the HER2 gene were aided in the development of therapeutic anti-HER2 agents and have offered insight on techniques to suppress this pathway.

\section{Trastuzumab}

Antitumor activity is facilitated by linking to the HER2 receptor's ECD, which results in antibody-dependent cell-mediated cytotoxicity (ADCC) and ligand-independent HER2 receptor dimerization obstruction. Anti-HER2 therapy's role has been reported to include suppression of downstream signal transduction pathways or angiogenesis, activation of cell-cycle arrest, apoptosis, or obstructing the restoration of DNA. Trastuzumab increases safety datasets and standard of living for women to progressive HER2-positive BC that is accepting chemotherapy. After doxorubicin treatment, trastuzumab is authorized exclusively to earlystage HER2-positive BC in collaboration with cytotoxic compounds including taxane $[68,69]$.

\section{Pertuzumab}

Pertuzumab is a humanized recombinant monoclonal antibody that inhibits HER2 proliferation through interacting with ligand-dependent HER3 mediated signaling pathway. Different downstream signaling systems, such as phosphoinositide 3-kinase (PI3K/AKT/mTOR) and the mitogen-activated protein kinase (RAS/RAF/MEK/ERK), are inactivated to achieve this. Pertuzumab, a companion to trastuzumab, causes an ADCC response and bonds to HER2 at a specific ECD than trastuzumab. While pertuzumab alone has only demonstrated moderate anti-HER2 efficacy, in combination with trastuzumab, it may have a synergistic impact. Pertuzumab can be useful in situations where HER2 levels are common but HER1 (EGFR) levels are elevated and reduced HER2 overexpression in BC s $[70,72]$.

\section{Novel tyrosine kinase inhibitors (TKIs) Lapatinib}

Lapatinib becomes the sole intracellular blocker permitted with each HER2 and EGFR receptors a similar period, resulting in stronger cumulative inhibitory action. It works a dual versatile TKI on both of such receptors, disrupting the MAPK/Erk1/2 and PI3K/AKT pathways along a course. In vitro experiments of lapatinib have displayed that enhances trastuzumab-dependent cell-mediated cytotoxicity toward BC cells. Lapatinib would be metabolized through a cytochrome P450 pathway through 3A4 isozyme, subsequent in a singular anti-EGFR metabolite that is independent of HER2 [71-74].

\section{Neratinib}

Neratinib represents an intrinsic pan-HER (HER1, 2, and 4) and EGFR TKI which opposes the PI3K/Akt and MAPK signaling pathways since the HER2 receptor is activated. Neratinib has proven to be beneficial in HER2-positive patients who have previously undergone trastuzumab and anti-HER2 medication. Neratinib was demonstrated to have a much more valid and reliable modulatory role in potential resistance mechanisms than lapatinib [75].

\section{Pyrotinib}

Pyrotinib is a small-fragment, unalterable Pan-ErbB receptor TKI that is part of a new class of HER2 targeting drugs. Pyrotinib links covalently to adenosine triphosphate (ATP)-binding sites with HER1, HER2, and HER4 intracellular kinase regions. This prevents its development of HER group homodimers, stops downstream signaling pathways from being activated, and slows tumor cell development. According to the revolutionary phase II clinical findings, the progression-free survival (PFS) reached out for 18.1 months [76].

\section{Afatinib}

Afatinib is a drug that blocks the HER1, 2, and 4 receptors irreversibly. Afatinib is a new aniline quinazoline drug that is orally bioavailable. This agent inhibits EGFR/HER1, HER2, and HER4 tyrosine kinase function in a potent, permanent, and highly selective manner. It associates covalently with cysteine in the ATP-binding sites of EGFR and HER2 almost half-maximal inhibitory concentrations were 0.5$14 \mathrm{~nm}$. Afatinib also stops EGFR/HER1 and HER2-containing dimers from developing. Suppression of these receptors, which are related to cell expansion and apoptosis inhibition, could be important in tumor growth control. Afatinib's preclinical efficacy had been seen in the variability of tumor models, such as EGFR and HER2-overexpressing trastuzumab-resistant cell lines (SUM 190-PT), HER2-negative cell lines (SUM 149-PT), and various in vivo studies [77].

\section{Inhibitors of PI3K/Akt/mTOR pathway}

Hormone resistance is allied by PI3K-Akt-mTOR signaling pathway. The PI3K catalytic subunit p110 (PIK3CA) is among the most commonly mutated and amplified genes, and this is enabled across over $70 \%$ of BC. Combination therapies that affect equally HR and the PI3K/Akt/mTOR pathways were studied in hopes of reversing hormone resistance [78].

\section{PI3K Inhibitors}

A mixture of PI3K inhibitors and aromatase inhibitors are employed in second-line therapy to HR+/HER advanced BC. Although buparlisib (pan-class I PI3K inhibitor) proven to boost PFS, particularly among some with a PIK3CA alteration, buparlisib, pictillisib, pilaralisib, voxtalisib (mTOR inhibitor) haven't yet seen to have meaningful health evidence leading to excessive toxic effects. Its most efficient and far less harmful PI3K inhibitors (Alpeisib, Taselisib), which are reportedly by phase III trials, have shown positive effects especially in $\mathrm{BC}$ patients with the PIK3CA mutation Pictilisib and taselisib were observed to improve antitumor activity when used for neoadjuvant therapy by letrozole and anastrozole conjunction for HR+/HER2 early BC, independent of PIK3CA function. Buparlisb and alpelisib are currently being studied in phase II [78-80].

\section{mTOR inhibitors}

The USFDA had authorized everolimus in mixture with exemestane for $\mathrm{HR}+$ advanced $\mathrm{BC}$ after letrozole or anastrozole treatment failure. Temsirolimus on the opposite side refused to produce any therapeutic effects in advanced $\mathrm{HR}+\mathrm{BC}$, whether used as first-line treatment in tandem alongside letrozole or second-line therapy alone [81].

\section{Histone deacetylase (HDAC) inhibitors}

Hormonal resistance can be affected through the lack of ER expression mediated by histone deacetylation in ER+ patients. HDAC inhibitors, that upregulated ER and aromatase function while inhibiting growth factor signaling pathways, could be able to counteract it. Either entinostat and vorinostat demonstrated increased anticancer effectiveness after consumed in a mixture alongside exemestane and tamoxifen as second-line therapy for HR+ advanced BC likened toward exemestane/ tamoxifen isolated [82].

\section{Steroid sulfatase inhibitors}

The enzyme steroid sulfatase regulates the transformation of dormant sulfate-conjugated steroids into productive and estrogenic non-conjugated steroids. Steroid sulfatase expression and enzyme activity are determined to a significantly higher in ER-positive BC. As 
a consequence, inhibiting steroid sulfatase is a rational way to reduce estrogenic steroids which can encourage BC development. A current phase-II trial found that combining irosustat (Steroid sulfatase inhibitor) with an aromatase inhibitor is safe or efficient. Another recent double operating steroid sulfatase inhibitor (SR16157), that prevents steroid sulfatase explicitly while also releasing a specific ER modulator had become intentional in hormone-dependent $\mathrm{BC}[83,84]$.

\section{Programmed death-1 (PD-1) and PD-L1 antibodies}

Antibodies with cytotoxic T-lymphocyte antigen 4, PD-1 and PD-L1 have enhanced health results and overall survival in TNBC patients through disrupting immunologic proteins that modulate an immune system. TNBC patients have greater TILs and better PD-L1 protein or TIL values above a certain threshold are linked to weak prognostic clinicopathologic characteristics, such as ER negativity, advanced rating, superior proliferative intensity, or LN optimism $[58,85,86]$.

\section{Pembrolizumab}

Pembrolizumab is a humanized monoclonal IgG4 antibody alongside PD-1 which works by preventing PD-1 through sticking to their ligands, PD-L1 and PD-L2. In certain nations, pembrolizumab is permitted a second-line therapy for advanced melanoma, non-small cell lung cancer for some cases, that is, head and neck squamous cell carcinoma. In contrast, clinical trials of pembrolizumab have shown positive effects in the variability of advanced cancers, such as gastric cancer and urothelial cancer, with longlasting results and a reasonable health impact $[58,87,88]$.

\section{Atezolizumab}

Atezolizumab is a humanized IgG1 monoclonal antibody that inhibits PD-L1 from interfering with the PD-1 and B7-1 receptors. It has been accepted for the treatment with metastatic non-small cell lung cancer and metastatic urothelial carcinoma in the United States. In primary phase trials, atezolizumab showed activity in TNBC when used in conjunction with chemotherapy, and it is now undergoing tested as a phase III trial [58].

\section{Nivolumab}

Nivolumab is the world's first PD-1 targeting antibody, has been authorized for use in a metastatic tumor, metastatic non-small cell lung cancer, progressive renal cell carcinoma, typical Hodgkin lymphoma, and persistent/metastatic squamous cell carcinoma of the head and neck. There has been no significant clinical finding for nivolumabtreated BC, although multiple trials are currently underway to assess its quality and efficacy with nivolumab for a monotherapy or combination treatment for such condition $[89,90]$.

\section{Avelumab}

The FDA recently approved Avelumab, a completely human anti-PD-L1 IgG1 antibody, for the management of metastatic Merkel cell carcinoma. Avelumab was being found to activate adaptive as well as innate immune mechanisms. Although several mAbs targeting the PD-1/PDL1 pathway have been licensed, avelumab is unusual since it could initiate ADCC while maintaining a native Fc-region. Many other licensed anticancer mAbs, such as necitumumab, pertuzumab, cetuximab, rituximab, and trastuzumab, have shown ADCC as a safety profile. While there was some speculation that avelumab could trigger lysis of stimulated immune cells allied with the presence of PD-L1 appearance on such cells, both preclinical and clinical studies have found limited or no rise in avelumab-mediated lysis of PD-L1+ immune cells, possibly leading to a low concentration of PD-L1 on immune cells relative to tumor cells [91-93].

\section{Poly ADP-ribose polymerase (PARP) inhibitors}

The DNA damage response, an interconnected set of molecular pathways that detect DNA impairment, halt the cell cycle or initiate DNA restoration, which defends healthy cells against the damaging impact of DNA damage. PARPs (poly [ADP-ribose] polymerase) are nuclear enzymes that promote DNA restoration by catalyzing the transition of ADP ribose from NAD+ to target proteins. PARP1 catalysis DNA repair by binding to weakened DNA in single-strand DNA breaks and other DNA lesions. By poly (ADP)-ribosylation of several nuclear proteins involved by chromatin arrest, PARP inhibits intracellular signaling pathways that amplify cell survival and DNA repair. Double-strand breaks occur when PARP is inhibited in replicating cells. In cells with wild-type BRCA1/2, double-strand breaks were restored by homologous recombination, but DNA strand breaks in BRCA1/2-deficient cells of homologous recombination deficiency are repaired by PARP1 compatibility. As a result, RNA interference or chemical inhibitors that suppress PARP1 cause extreme, exceedingly discerning toxicity in BRCA1/2-deficient cells, a phenomenon is known as synthetic accuracy $[58,94]$.

\section{Iniparib}

Iniparib, an interventional anticancer drug, was first formulated as a PARP inhibitor. In tumor cell lines, iniparib causes the initiation of -H2AX foci (a marker of DNA damage) as well as cell-cycle obstruct in the G2/M process. In tumor cell lines, iniparib stimulates the cellcycle impact of DNA damaging approaches, and it has antiproliferative efficacy in TNBC-related cell lines $[95,96]$.

\section{Fulvestrant}

Fulvestrant is an ER antagonist to a unique mechanism of action, making it a novel endocrine treatment. Fulvestrant is a 7a-alkylsulphinyl analog with $17 \mathrm{~b}$-oestradiol that varies in chemical composition among their nonsteroidal compositions comprising tamoxifen, raloxifene, as well as certain SERMs. Fulvestrant binds to estradiol $89 \%$ of the time but just $2.5 \%$ of the time to tamoxifen, making it a powerful inhibitor of estradiol bound to ER. Fulvestrant-ER linking inhibits receptor dimerization or liveliness-reliant on nucleo-cytoplasmic transferring, preventing the receptor from locating in the nucleus. Furthermore, since equally AF1 and AF2 are impaired, every fulvestrant-ER compound which reaches to nucleus transcriptionally remains immobile or never a detectable agonist action. Eventually, unlike estradiol- or tamoxifen-bound ER, the fulvestrant-ER complex is unstable, leading to rapid ER protein deterioration and absolute suppression of estrogen signaling that is recognized as selective ER down regulator $[97,98]$.

\section{T-DM1 and other ADCs}

T-DM1 is a dynamic molecule made up of trastuzumab, a solid thioether ligand, and maytansine derivate (DM1) anticancer drug. This is the first ADC that has been developed specifically for HER2-positive BC therapy. T-DM1 binding with HER2-positive cells enables the compound to be internalized through endocytosis, followed by an intraliposomal proteolytic breakdown and the activation of active DM1. The optimal acceptable dosage was established in phase I, II clinical studies to be $3.6 \mathrm{mg} / \mathrm{kg} / 3$ weeks, of bone marrow repression and hepatotoxicity as dose-preventive toxicity. The medicine has a half-life of 3.5 days and a clearance of $12.9 \mathrm{ml} /$ day $/ \mathrm{kg}(3.4 \mathrm{ml} /$ day $/ \mathrm{kg})$. ADCs constitute biological agents that develop a monoclonal antibody that is covalently bound to the cytotoxic agent by a synthetic coupler. The ADC is programmed to release the cytotoxic agent within the target cell as it enters it, protecting non-tumor cells from destruction [99,100].

\section{Innovative/novel chemotherapies \\ Anti-angiogenic agents}

TNBC has significantly higher intra-tumoral expression to VEGF which is a key angiogenic factor than non-TNBC BC. Anti-VEGF monoclonal antibody bevacizumab blocks cancer neovascular development or metastasis. The application of bevacizumab for first-line chemotherapy (docetaxel) increased reaction \% age (Placebo + Docetaxel: 46\% vs. Bevacizumab + Docetaxel: $64 \%$ ) besides median PFS (Placebo + Docetaxel-8 months vs. Bevacizumab + Docetaxel-10 months) in metastatic TNBC (phase III) (HR, 0.67; $\mathrm{p} \leq 0.001$ ). Crucially, combining bevacizumab with docetaxel has no discernible effect on the regimen's total protection level $[78,101]$.

\section{EGFR inhibitors}

In TNBC, the epidermal growth factor receptor (EGFR) is upregulated. Some phase II trials are currently appraising the effectiveness of 
cetuximab (anti-EGFR monoclonal antibody) to a conjunction of cisplatin through metastatic TNBC. Although there was only a moderate objective response rate (ORR-Cisplatin + cetuximab $(20 \%) \mathrm{v} / \mathrm{s}$ cisplatin only (10\%), cisplatin + cetuximab led to long intermediate PFS (3.7 vs. 1.5 months) and intermediate OS (12.9 vs. 9.4 months) than cisplatin by itself. Efforts are currently underway to classify a subset of TNBC patients who are most inclined to react to EGFR inhibitors. Low alpha B chain expression, elevated PTEN expression, and the absence of KRAS expression in tumors can all be associated with a beneficial outcome [78,102].

\section{Monoclonal antibodies}

Glembatumumab vedotin is a cytotoxic monoclonal antibody derivative that marks glycoprotein NMB overexpression (gpNMB+) cells. In $40 \%$ of cases of TNBC, the gpNMB transmembrane protein attributed to tumor invasion and metastasis become upregulated. Comparison to the medication of physician's choosing, glembatumumab vedotin greatly increased PFS and OS in gpNMB+ progressive TNBC patients in phase II trial [103].

\section{Immunotherapies}

Pembrolizumab was an anti-programmed cell death-1 receptor antibody made by a human monoclonal IgG4 antibody (PD-1). It was exhibited therapeutically efficient and healthy in progressive TNBC patients by blocking $\mathrm{T}$ cells or stopping/averting the immune system from abolishing cancer cells through inhibits of PD-1 autoimmunity. Although patients with PD-L1 progressive TNBC existed to be chosen for phase Ib trial, alternative continuing phase II trial/study found that pembrolizumab's antitumor function was independent of PD-L1 expression. Pembrolizumab also demonstrated long-term antitumor efficacy in patients of metastatic TNBC that had been extensively pretreated $[78,104]$.

\section{Nab-paclitaxel}

Albumin-bound paclitaxel, the second generation of taxanes was designed to increase the paclitaxel therapeutic index while dropping the toxic effects correlated with Taxol, CrEL, and ethanol vehicles. Since it does not need steroid or antihistamine premedication, nab-paclitaxel is a successful option due to its efficacy; nab-paclitaxel could be given with larger dosages in lesser duration, leading to a better drug Cmax and AUC in the blood. Intravenous injection of nab-paclitaxel reacts through albumin and paclitaxel in fine particles of 8-30 nm, instead quickly allocates to the extravascular space and specifically using endogenous albumin transport pathways to administer higher doses of nab-paclitaxel to tumors. In 2005, FDA permitted nab-paclitaxel to MBC management. Since then, it's been tested in some concentrations and settings on a range of $\mathrm{BC}$ therapy classes $[58,105]$.

\section{Eribulin}

Eribulin mesylate recognized conceptually modified synthetic halichondrin B derivative that is, discovered in two unrelated sponge animals, Halichondria okadaic Kadota and Aninella sp., upwards of 20 years ago. It's a nontaxane microtubule inhibitor that's been the single cytotoxic component to improve optimum protection in MBC patients who've been heavily pretreated in recent years. Eribulin inhibits microtubule polymerization through an eribulin-specific active position in-tubulin, with no effect on microtubule depolymerization, unlike typical anti-tubulin agents such as taxanes, epothilones, and vinca alkaloids. It may have antitumor properties by influencing epithelial-to-mesenchymal transition and tumor vasculature remodeling. Potential studies are required to better understand eribulin's function in MBC care, both in terms of patient selection and clinical trial location. Eribulin can often be used as first-line therapy in progressive BC both adjuvant and neoadjuvant and in conjunction with other treatments such as biologics $[106,107]$.

\section{Utidelone}

MBC that is resistant to anthracyclines and taxanes is also a major indicator of disease development. The myxobacterium Sorangium cellulosum produces epothilones, a family of naturally occurring microtubule inhibitors. Epothilones have a different molecular composition and mode of action than taxanes. Patients with tumors that are immune to taxanes are also vulnerable to epothilones. Utidelone would be a hereditarily modified epothilone equivalent to outperform ixabepilone, so that's the one drug on such category permitted through USFDA for its better potency, efficacy, and cost-effectiveness. Utidelone has demonstrated potential in many clinical studies as a possible therapy for highly pretreated drugresistant progressive BC. More research is required to improve the composition of utidelone for easier administration and to lower the risk of peripheral neuropathy. Current studies among utidelone function in the initial stages of $\mathrm{BC}$, as well as analyses combining utidelone to other biological immunotherapies and selective agents [58,108].

\section{DIAGNOSIS AND MANAGEMENT OF BREAST CANCER}

The diagnosis and management of breast cancer are described as (Fig. 5).

\section{Physical assessment and clinical history}

The health/clinical record among BC victims are utilized for used to measure cancer threats and to demonstrate the prevalence or lack of signs that are predictive of $\mathrm{BC}$, such as menarche age, menopausal status, early pregnancies, and postmenopausal hormone replacement therapy and oral contraceptives usage. Personal history covers the age of $\mathrm{BC}$ detection, past breast biopsies, and therapy of radiation for other cancers. Family history involves the background of ovarian cancers or first-degree relations in BC [46].

The patient must be monitored with specific symptoms such as breast pain, nipple ejection, malaise, bony pain, or weight loss after the predicted probability for BC. Physical examination includes nipple changes, asymmetry or apparent mass, and also changes such as dimpling, erythema, proud orange might be examined on the skin.

\section{Diagnostic imaging}

\section{Mammography}

Mammography was a kind of limited X-ray and also a much more sensitive process to diagnosis small BCs. X-ray mammography which examines premature $\mathrm{BCs}$ and observations must often along with clinical signs and if relevant, the outcomes of needle biopsy, that is, fine needle aspiration cytology (FNAC), and core biopsy, CB before focusing treatment. The procedure toward creating a visible picture where both breasts are placed under an X-ray machine and squeezed among two plates. If there is something abnormal in the breast tissue the mammography detected the early clinical mark of $\mathrm{BC}$ progression. The WHO suggests comprehensive mammography testing for women aged 40-49 and 70-75 years just in the sense of thorough studies in an excellent context. In some instances, the positive effects of digital

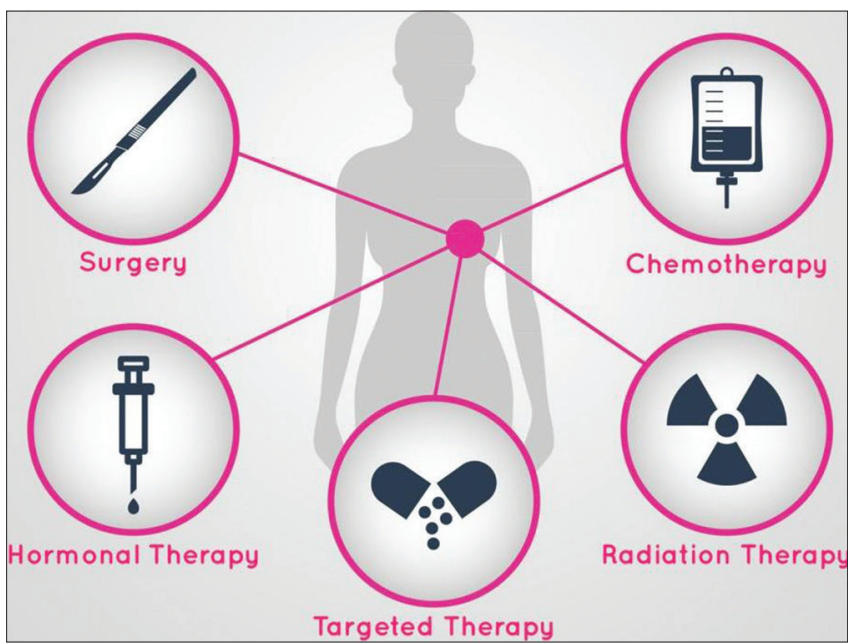

Fig. 5: Diagnosis and management of breast cancer [126] 
mammography include using computer-aided identification, computer programs centered in algorithms that warn a radiologist for probable mammogram problems, or facilitate coordinated film reading [109-111].

Mammography inspection caused a 19\% average decrease in death from BC, with much fewer benefits to women of the 40 s $(15 \%)$ or greater benefits in the 60 s (32\%). In women starting screening among 40-50 years of age, mammography does have a $61 \%$ risk of the inaccurate outcome over 10 years [31,112]

\section{MRI}

MRI is a powerful imaging method that creates high-resolution images without the use of damaging radioactive being needed. MRI usages magnetic fields or radio waves to create accurate pictures of the interior body. Typically, an MRI scanner is a long tube with powerful magnets. During a scan, that requires 15-90 min, you lay within the chamber. As these are never included in part of regular examinations, an MRI scan may be depleted in some cases. MRI offers quite detailed outcomes or consistent advantages for people who grow BC caused by genetic variations in BRCA1 or BRAC2 or have axillary lymphadenopathy, multifocal disorder, or undefined results are provided by a mammogram and ultrasound. While breast MRI detects potential pathology as in contralateral breast about $3 \%$ of period, preoperative breast MRI metaanalyses have indicated an improvement in mastectomy levels but no increase in population control subsequent breast-conserving surgery (BCS) or radiation therapy. Present guidelines for breast MRI involve assessment of patients through an augmentation-limited mammographic assessment, estimation of nature of the condition only at a period of early $\mathrm{BC}$ detection, analysis of inconclusive clinical test results, mammography and ultrasonography, contralateral breast diagnosing of specified patients with early breast carcinoma or asymptomatic surveillance of patients at extreme threat of breast carcinoma [109,112].

\section{Breast biopsy}

Breast biopsies are the most accurate and effective tool for detecting BC. Various forms of breast biopsies remain available. Breast imaging, clinical breast analysis, or biopsy being conducted together to increase medical accuracy or to get out of several negative result findings as practicable (triple test). Stereotactic heart biopsy supported by vacuum. BC is diagnosed by surgical biopsy and two categories of needle biopsies: FNAC and core needle biopsy [111].

\section{Ultrasound}

Ultrasound usages sound waves of an elevated intensity/frequency (at least $10 \mathrm{MHz}$ ) will build a picture of the interior body. The ultrasound will indicate the size and position of the tumor if a lump was hard or even a cyst filled with fluid. This inspection is increasingly being a standard practice in young women to detect lumps $[31,40]$.

While ultrasound is useful for detecting malignancy, it cannot definitively distinguish benign and malignant solid lesions throughout the breast. Ultrasound usage in the breast clinic decreases to $6 \%$ the level of unsafe biopsies to medically and mammographically irregular lumps. While assisting to aspirate thin, intensely located cysts, it is helpful. Lacking the ultrasound to direct a breast expert, they can be overlooked by a fine needle [109].

Present criteria for breast ultrasonography involve measurable reports of defects or alleged mammography and MRI problems, breast implant complications, possible intrinsic masses in the microcalcification context or mammography design distortions, supplementary screenings of women with elevated BC who aren't suitable to and have no instant access for MRI and assumed axillary lymphadenopathy [31].

\section{Surgery}

$\mathrm{BC}$ surgery has two main targets: to extract a tumor from the breast or to assess the disease stage. BCS and mastectomy were used in surgical BC treatment. Just cancerous tissue with an edge of benign tissue is eliminated during BCS. Separation of a whole breast involves minimal or complete mastectomy. Improved radical mastectomy requires the elimination of the whole breast or underarm LNs, they will not require removal of the underlying muscle of a chest wall, such as in radical mastectomy [40].

Initial breast tumor ablation is maybe the initial or second stage of treatment following initial systemic therapy constructed on tumor magnitude, tumor association to breast size, tumor pathology, comorbidity, and patient preference. The surgical degree will be focused on the "real" tumor edges since neoadjuvant systemic therapy [30].

More significantly, the strategy for sectioning of lymph nodes (SLN) becomes prominent since it allows much fewer LNs to be removed, leading to lesser side effects. Developments of SLN imaging during the last few years had improved their sensitivity for SLN recognition to $80 \%$ utilizing blue dye itself with 92-98\% employing multiple mechanisms [47].

\section{Lumpectomy}

The healthy tissue underlying a breast tumor is removed in this procedure, but the overall shape of the breast or nipple is preserved. As per the American cancer society, lumpectomy and partial mastectomy become a method for separating that breast portion which includes a malignant tumor involving certain normal tissues or associated LNs keeping as much portion of the breast preserved as necessary. Even so, tenderness, transient inflammation, sclerosis, and altered breast shape are the side effects of lumpectomy $[41,42,113]$

\section{Mastectomy}

Mastectomy is performed to lessen the probability/chances for BC progression, yet this may not fully remove its risk of getting cancer. This procedure requires separating the whole breast without removing any LNs. Mastectomy is believed to be the most successful issue to interact from an already widespread context of cancer in which lumpectomy wasn't sufficiently important [29,41].

If you choose chemotherapy, HT, or targeted therapy, the option for surgery would not involve it. Depending on the existence of a tumor, the treatments were listed, not the sort of procedure that may need. The full longevity of lumpectomy or radiation treatment is similar to the mastectomy form of surgery [29]. Pain, numbness, and lymphedema can be the most frequent consequence of surgery once LNs have been extracted and diagnosed by radiation therapy $[16,29,114]$.

\section{Radiation therapy}

Radiotherapy is a method of treatment that involves radiation exposure destroying a DNA in tumor cells (breast, chest wall, or underarm region) to cause their cell death; this form of radiation is represented as ionizing radiation. During breast-conserving procedures, radiotherapy was typically offered and is even possible provided during mastectomy. Radiotherapy can be made available to advanced cancer patients, that is inoperative despite systemic therapy but may be regarded for managing their effects with tumor cells and remote metastases in those cancer patients or to increase patient safety. Radiation treatment was found to lower the incidence of developing cancer by around $50 \%$ or the threat to $\mathrm{BC}$ mortality of around $20 \%$. The advances in the use of radiation therapy in BC treatment such as 3D Conformal radiotherapy, Intensitymodulated radiation therapy, Stereotactic body radiation therapy, Particle radiations (electron, proton, and neutron beams). Some side effect is seen in the breast before and after the radiation therapy such as fatigue, rough to touch, red, swallowed and sore $[14,30,40,113]$.

\section{Systemic therapy}

Systemic therapy is often a therapy that passes through the bloodstream or alters all areas of the body but not only tumors. These tumor medications are administered orally or intravenously. Chemotherapy, HT, and targeted therapy being employed in systematic therapy, both of which function by various processes. These tumor medications were administered and delivered through the mouth into a vein. It's also considered neoadjuvant therapy if systemic therapy was offered for patients before surgery. The cancer is also enough diminished to 
allow surgical removal necessary or to enable less intensive surgery. Neoadjuvant systemic therapy has been seen to be as efficient as a therapy to promote longevity, disease progression, or reduce the incidence, provided during surgery. Systemic treatment is offered for patients during surgery called adjuvant therapy [45,115].

\section{Chemotherapy}

The procedure for treating and terminate cancer cells (Triple-negative, HER2+, luminal B-such as BCs) using such medications described as chemotherapy. Based on a patient's state, it may be provided in all cases that are in pre and post-surgery. It is normally defined across 3-6 months, including days and weeks off between therapy will allow the body potential of recovery to tumor or chemotherapy duration often varies on a category or mixture of medications being used for BC treatment. As per the American cancer society, all drugs comprised for chemotherapy such as Docetaxel, Paclitaxel, Platinum agents (cisplatin, carboplatin), Vinorelbine (Navelbine), Capecitabine (Xeloda), Liposomal doxorubicin (Doxil), Cyclophosphamide (Cytoxan), Carboplatinin, (Paraplatin) but it has different side effects. This can be harder to cure the metastases and secondary breast, but this can be managed and even for different decades. Short-term adverse effects of chemotherapy may comprise hair loss, vomiting nausea, stiffness of finger or toenail, mouth ulcers, fatigue, or reduced counts in blood cells, while long-term adverse effects can be seen are premature menopause, weight gain, memory and concentration problems associated with a combination of medication $[29,40]$.

\section{Endocrine therapies}

The goal of endocrine therapy is to decrease the impact of estrogen on positive ER BCs. It's the most significant method of systemic therapy in ER-positive tumors, that is, often termed as hormone-dependent tumors. There seems to be a range of forms of endocrine therapy that are taken by mouth or given as either an injection incorporates selective ER modulators, selective ER down regulators, Aromatase inhibitors, Gonadotrophin-releasing hormone analogs. HT medications were slower but inhibit the growth of positive tumors regulated by a HR through blocking cancer cells from obtaining their hormones that want to expand. Tamoxifen or aromatase inhibitors, such as the medicine, were recommended or administered each 5-10 years of pill form. Another similar type of HT is ovarian suppression, which will stop ovaries from stimulation of estrogen by medicine and surgery. The adverse effects caused by HT involve menopausal complications such as hot flashes, joint and muscle joint pain $[40,45]$.

\section{Targeted therapy}

Drugs that disrupt particular signaling mechanisms in cancer cells that help to develop are targeted therapies. Anti-HER2 drugs, CDK4/6 inhibitors, mTOR inhibitors, PARP inhibitors, and VEGF inhibitors have also been used for BC treatment. Targeted therapy plays a crucial function in killing or damaging cancer cells with different markers and proteins, that is, HER2-positive BC. These already have targeted and are focusing on cancers that have specific markers and proteins which cannot be used by anyone. A great deal of hope for possible BC treatment is also indicated by targeted therapies. The consequence of targeted therapy depends on what treatment has been provided $[14,116]$.

\section{FUTURE PROSPECTIVE IN BREAST CANCER TREATMENT}

\section{Nanotechnology}

Nanotechnology has a major function through carrying drugs in a targeted way to cancer cells to reducing its systemic toxicity of anticancer drugs or reducing the health-associated standard of life and to provide very less harmful and more reliable treatment against $\mathrm{BC}$ as compared to chemotherapy. NP drug molecules are composed of approximately two substances, each of which is an active drug and the other component represents an NP framework utilized to increase the system targeting. Nanotechnology applies to relations in molecular and cellular elements or engineered substances usually; fragments in atoms or molecules through extremely small particles, varying from
1 to $100 \mathrm{~nm}$ seem to be more desirable as they have greater drug loading potential. NPs provide the medication with several beneficial properties, such as prolonged elimination cycles, improved drugsite interaction time, modifying its physicochemical properties or pharmacokinetics profiles decreased drug resistance.

Furthermore, NPs provide a forum of custom-tailored innovative therapy structure, by enabling a binding with different supporting moieties through a ligand such as stimulus-responsive peptides and polymers, protective PEGylation substrate, cell-penetrating peptides, targeting moiety, as well as antibodies. They often allow a multipurpose system to be developed that integrates numerous beneficial mediator's ineffective treatment include lipid-based drug carriers, polymeric nanoparticles (liposomes), carbon nanotubes, viral nanomaterials, Nanoshells, and inorganic nanoparticles [3,114].

As demonstrated repeatedly there are far more least 150 underway clinical studies assessing the effectiveness of nanotechnology-based drug delivery carriers which address cancer, the nanotechnology function has expanded rapidly. In either an attempt to boost a therapeutic index of modern doxorubicin chemotherapy while preserving's antitumor efficacy, numerous liposomal doxorubicin formulations have been developed. The potency in three liposomal doxorubicins, such as liposomal daunorubicin (DaunoXome), liposomal doxorubicin (D-99, Myocet ${ }^{\mathrm{TM}}$ J) or pegylated liposomal doxorubicin are common will be used [42].

\section{Gene therapy}

Gene therapy is now a corrective technique that is deemed to rectify specific molecular defects linked with progression and growth with BC. Altered BRCA1 or p53 genes identified just such as cancer inclination genes were also implicated in oncogenesis. Present understanding of proto-oncogene or tumor suppressor genes with information on malignancy had been encouraged its expansion gene therapy strategies aimed toward the regrowth and ablation of these genes. In certain strategies, cancer cells were provided to the potential of transform the systemically administered drug onto a toxicant and its trigger for degradation through imitating viral vectors, while transferring drug resistance genes in healthy cells will offer chemoprotection across large antineoplastic therapy. Immune system regulation will eventually lead to anti-cancer drug resistance $[29,42,117]$.

\section{Oncogene inactivation}

There have been many oncogenic proteins reported or linked to different cancer/malignancies. Until recently, the most popular clinical trial approach was to use antisense strategies. Oncogene transcription can be blocked by the use of adenoviral gene E1A which interferes in erbB-2 transcription, a technique that's also helpful in the treatment for cancers that up regulated its oncogenic protein, such as ovarian and BC $[42,117]$

\section{Enhancement of tumor-suppressor genes}

Over 24 tumor suppressor genes were recognized, and a variety of cancer was correlated to defects in such genes. Adenoviral vectors are being used in many clinical trials to deliver p53 to cancer cells. Viral vectors were also used to insert the gene for retinoblastoma and the gene for BC BRCA1 across bladder or ovarian cancer. This strategy would collapse in certain cases since the mutated gene shows superior adverse effects on a regular gene. A genetic modification technique instead of a gene augmentation strategy will be more efficient for overcome such issues of p53 gene therapy [7].

\section{Chemoprotection approach}

In this respect, significant focus has been paid to the MDR-1 gene encrypting a multiple complex drug therapy transporter protein (P-glycoprotein). Variety of chemotherapeutic substances (doxorubicin, vinca alkaloids, epipodophyllotoxins, and paclitaxel) or additional medications are transferred to cells by this transmembrane protein, thereby shielding us from the negative impacts of substances. 


\section{Virus-mediated oncolysis}

Lysis tumor cells may be affected by some viruses, such as adenovirus or HSV-1. when combined with another gene-based antineoplastic approach, usage of oncolytic viruses may arise as a potential contribution to multidimensional cancer therapy. Selective virus replication to tumor cells resulting in cell lysis or local propagation in adjacent cancer cells with the infectious viral progeny. The replicationcompetent adenovirus or HSV-1 has been used in several interventional applications of such a technique $[7,42]$.

\section{Immunomodulation}

Different cytokines may boost cancer cell immunity, yet this discovery has prompted the production of gene-based strategies that attenuate malignant immune reactions.

\section{Ectopic cytokine expression}

Some cytokines were shown to reduce tumor development where they are ectopically distributed within or in the microenvironment for tumor cells. Some immunostimulant agents do not instantly modify a tumor growth rate, although unless an animal becomes subsequently confronted by wild-type tumor cells, they contribute to immunity toward tumor growth.

\section{Immune enhancement}

The one strategy would be to release highly immunogenic molecules, such as MHC allotype antigens, on the exterior to cancer cells. To accomplish T-cell activation, these have long been established that alternate costimulatory pathways apart since T-cell remain necessary. This one mechanism is activated by B7-1 (CD 80) and B7-2 (CD 86) residues. In combination with antigen linking with T-cell receptor, B7s, which presence was usually restricted to antigen-presenting cells or certain specific immune effector cells, recruit particular receptors onto a $\mathrm{T}$ cells substrate $[7,42,118]$

\section{Human antimicrobial protein Hcap18/11-37 in BC}

Human antimicrobial protein Hcap18/1l-37 becomes a multifunctional protein that is involved in antimicrobial resistance through inducing chemotaxis, stimulating gliogenesis, and encouraging tissue recovery. The Hcap18/LL-37 protein plays a significant function in the development of BC cells [119].

\section{Genetic distinction in stromal proteins (Decorin and Lumican) in} BC

Stromal protein was its protective structure in physiologic tissue within the breast. Alteration in stromal proteins- decorin and lumican regulate the development of BC [120].

\section{Prognostic relevance of tumor precise HMG-CoA reductase in $\mathrm{BC}$} HMG-CoA in mevalonate pathways is linked to tumor progression. However, the importance of HMG-CoA in a broad populace in BC patients was investigated in current analyses [121].

\section{ACKNOWLEDGMENT}

I would like to express my thanks to the CT Institute of Pharmaceutical Sciences, Jalandhar, and the management of the CT Group of Institutions, Jalandhar for providing support, guidance, suggestion, and excellent research facilities.

\section{AUTHOR CONTRIBUTIONS}

All the authors have contributed equally.

\section{CONFLICT OF INTEREST}

There are no conflicts of interest.

\section{FUNDING}

Nil.

\section{REFERENCES}

1. El Hachem G, Gombos A, Awada A. Recent advances in understanding breast cancer and emerging therapies with a focus on luminal and triplenegative breast cancer. F1000Res 2019;8:F1000 Faculty Rev-591.

2. Abreu PH, Santos MS, Abreu MH, Andrade B, Silva DC. Predicting breast cancer recurrence using machine learning techniques: A systematic review. ACM Comput Surv 2016;49:1-40.

3. Feng Y, Spezia M, Huang S, Yuan C, Zeng Z, Zhang L, et al. Breast cancer development and progression: Risk factors, cancer stem cells, signaling pathways, genomics, and molecular pathogenesis. Genes Dis 2018;5:77-106.

4. Tinoco G, Warsch S, Glück S, Avancha K, Montero AJ. Treating breast cancer in the $21^{\text {st }}$ century: emerging biological therapies. J Cancer 2013;4:117-32

5. Callahan R, Hurvitz S. Human epidermal growth factor receptor-2positive breast cancer: Current management of early, advanced, and recurrent disease. Curr Opin Obstet Gynecol 2011;23:37-43.

6. Rakha EA, Reis-Filho JS, Baehner F, Dabbs DJ, Decker T, Eusebi V, et al. Breast cancer prognostic classification in the molecular era: the role of histological grade. Breast Cancer Res 2010;12:207.

7. Tong $\mathrm{CW}, \mathrm{Wu} \mathrm{M}$, Cho WC, To KK. Recent advances in the treatment of breast cancer. Front Oncol 2018;8:227.

8. Mir O, Berveiller P, Ropert S, Goffinet F, Pons G, Treluyer JM, et al. Emerging therapeutic options for breast cancer chemotherapy during pregnancy. Ann Oncol 2008;19:607-13.

9. Key TJ, Schatzkin A, Willett WC, Allen NE, Spencer EA, Travis RC. Diet, nutrition, and the prevention of cancer. Public Health Nutr 2004; 7:187-200

10. Cardoso F, Harbeck N, Barrios CH, Bergh J, Cortés J, El Saghir N, et al. Research needs in breast cancer. Ann Oncol 2017;28:208-17.

11. Al-Wajeeh AS, Salhimi SM, Al-Mansoub MA, Khalid IA, Harvey TM, Latiff A, et al. Comparative proteomic analysis of different stages of breast cancer tissues using ultra-high-performance liquid chromatography-tandem mass spectrometer. PLoS One 2020;15:e0227404.

12. DeSantis CE, Ma J, Gaudet MM, Newman LA, Miller KD, Sauer AG, et al. Breast cancer statistics. CA Cancer J Clin 2019;69:438-51.

13. Allen T, Razavi GS, Giridhar MN. A review article on emerging role of hybrid molecules in treatment of breast cancer. Austin J Clin Immunol 2014;1:1022.

14. Baskar R, Lee KA, Yeo R, Yeoh KW. Cancer and radiation therapy: Current advances and future directions. Int J Med Sci 2012;9:193-9.

15. Tfayli A, Temraz S, Mrad RA, Shamseddine A. Breast cancer in low- and middle-income countries: An emerging and challenging epidemic. J Oncol 2010;2010:490631.

16. Howell A, Anderson AS, Clarke RB, Duffy SW, Evans DG, GarciaClosas $\mathrm{M}$, et al. Risk determination and prevention of breast cancer. Breast Cancer Res 2014;16:446.

17. Murphy CG, Dickler MN. Endocrine resistance in hormone-responsive breast cancer: Mechanisms and therapeutic strategies. Endocr Relat Cancer 2016;23:R337-52.

18. Wang J, Xu B. Targeted therapeutic options and future perspectives for HER2-positive breast cancer. Signal Transduct Target Ther 2019;4:34.

19. Neophytou C, Boutsikos P, Papageorgis P. Molecular mechanisms and emerging therapeutic targets of triple-negative breast cancer metastasis. Front Oncol 2018;8:31.

20. Feng WW, Kurokawa M. Lipid metabolic reprogramming as an emerging mechanism of resistance to kinase inhibitors in breast cancer. Cancer Drug Resist 2020;3:100.

21. Madden R, Kosari S, Peterson GM, Bagheri N, Thomas J. Lapatinib plus capecitabine in patients with HER2-positive metastatic breast cancer: A systematic review. Int J Clin Pharmacol Ther 2018;56:72-80.

22. Qiu Y, Lu G, Wu Y. Upregulated CDKN2A Expression May be an Independent Protective Factor in Luminal-like Breast Cancer; 2020.

23. Freedman RA, Partridge AH. Emerging Data and Current Challenges for Young, Old, Obese, or Male Patients with Breast Cancer. Clin Cancer Res 2017;23:2647-54.

24. Dr. Ananya Mandal. Breast Cancer Pathophysiology; 2019. Available from: https://www.news-medical.net/health/Breast-CancerPathophysiology.aspx.

25. Waks AG, Winer EP. Breast cancer treatment: A review. JAMA 2019;321:288-300

26. Mary Ann Kosir. Breast Cancer; 2020. Available from: https://www. merckmanuals.com/professional/gynecology-and-obstetrics/breastdisorders/breast-cancer.

27. Eric Wong, Sultan Chaudhry, Marisa Rossi. Breast Cancer; 2011. 
Available from: http://www.pathophys.org/breast-cancer.

28. Allison KH. Molecular pathology of breast cancer: What a pathologist needs to know. Am J Clin Pathol 2012;138:770-80.

29. Breast Cancer; 2021. Available from: http://www.wikipedia.org.

30. Harbeck N, Penault-Llorca F, Cortes J, Gnant M, Houssami N, Poortmans P, et al. Breast cancer. Nat Rev Dis Prim 2019;5:66.

31. Shah R, Rosso K, Nathanson SD. Pathogenesis, prevention, diagnosis, and treatment of breast cancer. World J Clin Oncol 2014;5:283-98.

32. Mina LA, Lim S, Bahadur SW, Firoz AT. Immunotherapy for the treatment of breast cancer: Emerging new data. Breast Cancer (Dove Med Press) 2019;11:321-8.

33. Ballinger T, Kremer J, Miller K. Triple-negative breast cancer-review of current and emerging therapeutic strategies. Oncol Hematol Rev 2016;12:89-94.

34. Blanco E, Ferrari M. Emerging nanotherapeutic strategies in breast cancer. Breast 2014;23:10-8.

35. Landaverde D, Verma S. Recent treatment advances in HER2-positive metastatic breast cancer: A clinical approach. Clin Pract 2012;9:287-99.

36. Soysal SD, Tzankov A, Muenst SE. Role of the tumor microenvironment in breast cancer. Pathobiology 2015;82:142-52.

37. Nathan MR, Schmid P. The emerging world of breast cancer immunotherapy. Breast 2018;37:200-6.

38. American Cancer Society. Breast Cancer Facts and Figures 2019-2020. Atlanta: American Cancer Society, Inc.; 2019.

39. Sana M, Malik HJ. Current and emerging breast cancer biomarkers. J Cancer Res Ther 2015;11:508-13.

40. European Society for Medical Oncology (ESMO). 2018. Via Ginevra 4, 6900 Lugano, Switzerland. Available from: https://www.esmo. org/content/download/6593/114959/file/en-breast-cancer-guide-forpatients.pdf.

41. Dey $\mathrm{B}$, et al. A review article on breast cancer. Int J Pharm Pharm Res 2018;11:284-98.

42. Sharma GN, Dave R, Sanadya J, Sharma P, Sharma KK. Various types and management of breast cancer: An overview. J Adv Pharm Technol Res 2010;1:109-26.

43. Deshpande TM, Pandey AK, Shyama SK. Review: Breast cancer and etiology. Trends Med 2017;17:1-7.

44. Bhargava HD. Breast Cancer; 2020. Available from: https://www. webmd.com/breast-cancer/understanding-breast-cancer-basics.

45. El-Sharkawy A. In: Ahmed R, Al-Naggar A, editors. Principles and Practice of Cancer Prevention and Control Breast Cancer. Foster City, CA: Omics Group eBooks; 2014. p. 1-38.

46. Akram M, Iqbal M, Daniyal M, Khan AU. Awareness and current knowledge of breast cancer. Biol Res 2017;50:33.

47. O'Sullivan CC, Loprinzi CL, Haddad TC. Updates in the evaluation and management of breast cancer. Mayo Clin Proc 2018;93:794-807.

48. Breast Cancer: Stages. American Society of Clinical Oncology. Cancer Net; 2020. Available from: https://www.cancer.net/cancer-types/breastcancer/stages.

49. Koh J, Kim MJ. Introduction of a new staging system of breast cancer for radiologists: An emphasis on the prognostic stage. Korean J Radiol 2019;20:69-82

50. Abdulkareem IH. Aetio-pathogenesis of breast cancer. Niger Med J 2013;54:371-5

51. Sun YS, Zhao Z, Yang ZN, Xu F, Lu HJ, Zhu ZY, et al. Risk factors and preventions of breast cancer. Int J Biol Sci 2017;13:1387-97.

52. Meister MS, Morgan J. American Council on Science and Health; 2002. Available from: https://www.acsh.org/wp-content/ uploads/2012/04/20070814_risk_breast.pdf.

53. Rojas K, Stuckey A. Breast cancer epidemiology and risk factors. Clin Obstet Gynecol 2016;59:651-72.

54. Majeed W, Aslam B, Javed I, Khaliq T, Muhammad F, Ali A, et al. Breast cancer: Major risk factors and recent developments in treatment. Asian Pac J Cancer Prev 2014;15:3353-8.

55. Ikhuoria $\mathrm{EB}, \mathrm{Bach} \mathrm{C}$. Introduction to breast carcinogenesis symptoms, risks factors, treatment, and management. Eur J Eng Res Sci 2018;3:58-66.

56. Harris JR, Lippman ME, Morrow M, Osborne CK. Diseases of the Breast $5^{\text {th }}$ ed. Alphen aan den Rijn: Wolters Kluwer Health Adis (ESP); 2014.

57. Myoclinic. Breast Cancer; 2020. Available from: https://www. mayoclinic.org/diseases-conditions/breast-cancer/symptoms-causes/ syc-20352470.

58. Herndon J. A Comprehensive Guide to Breast Cancer; 2019. Available from: https://www.healthline.com/health/breast-cancer\#symptoms.

59. Hu X, Huang W, Fan M. Emerging therapies for breast cancer. J Hematol Oncol 2017;10:98.

60. Cancer Genome Atlas Network. Comprehensive molecular portraits of human breast tumors. Nature 2012;490:61-70.

61. Mohammed AA, Rashied H, Elsayed FM. CDK4/6 inhibitors in advanced breast cancer, what is beyond? Oncol Rev 2019;13:416.

62. Xu H, Yu S, Liu Q, Yuan X, Mani S, Pestell RG, et al. Recent advances of highly selective CDK4/6 inhibitors in breast cancer. J Hematol Oncol 2017;10:97.

63. Liu M, Liu H, Chen J. Mechanisms of the CDK4/6 inhibitor palbociclib (PD 0332991) and its future application in cancer treatment (Review). Oncol Rep 2018;39:901-11.

64. Dange Y, Bhinge S, Salunkhe V. Optimization and validation of RPHPLC method for simultaneous estimation of palbociclib and letrozole. Toxicol Mech Methods 2018;28:187-94.

65. Rader J, Russell MR, Hart LS, Nakazawa MS, Belcastro LT, Martinez D, et al. Dual CDK4/CDK6 inhibition induces cell-cycle arrest and senescence in neuroblastoma. Clin Cancer Res 2013;19:6173-82.

66. Corona SP, Generali D. Abemaciclib: A CDK4/6 inhibitor for the treatment of HR+/HER2- advanced breast cancer. Drug Des Devel Ther 2018;12:321-30.

67. Lallena MJ, Boehnke K, Torres R, Hermoso A, Amat J, Calsina B, et al. In-vitro characterization of abemaciclib pharmacology in $\mathrm{ER}+$ breast cancer cell lines. Cancer Res 2015;75:3101.

68. Spector NL, Blackwell KL. Understanding the mechanisms behind trastuzumab therapy for human epidermal growth factor receptor 2-positive breast cancer. J Clin Oncol 2009;27:5838-47.

69. Baselga J, Albanell J, Molina MA, Arribas J. Mechanism of action of trastuzumab and scientific update. Semin Oncol 2001;28:4-11.

70. von Minckwitz G, Procter M, de Azambuja E, Zardavas D, Benyunes M, Viale G, et al. Adjuvant pertuzumab and trastuzumab in early HER2positive breast cancer. N Engl J Med 2017;377:122-31

71. Capelan M, Pugliano L, De Azambuja E, Bozovic I, Saini KS, Sotiriou C, et al. Pertuzumab: New hope for patients with HER2positive breast cancer. Ann Oncol 2013;24:273-82.

72. Burris HA $3^{\text {rd }}$. Dual kinase inhibition in the treatment of breast cancer: Initial experience with the EGFR/ErbB-2 inhibitor lapatinib. Oncologist 2004;9:10-5

73. Oakman C, Pestrin M, Zafarana E, Cantisani E, Di Leo A. Role of lapatinib in the first-line treatment of patients with metastatic breast cancer. Cancer Manag Res 2010;2:13-25.

74. Zhang D, Pal A, Bornmann WG, Yamasaki F, Esteva FJ, Hortobagyi GN, et al. Activity of lapatinib is independent of EGFR expression level in HER2-overexpressing breast cancer cells. Mol Cancer Ther 2008; 7:1846-50.

75. Burstein HJ, Sun Y, Dirix LY, Jiang Z, Paridaens R, Tan AR, et al. Neratinib, an irreversible ErbB receptor tyrosine kinase inhibitor, in patients with advanced ErbB2-positive breast cancer. J Clin Oncol 2010;28:1301-7.

76. Gourd E. Pyrotinib shows activity in metastatic breast cancer. Lancet Oncol 2017:18:e643.

77. Geuna E, Montemurro F, Aglietta M, Valabrega G. Potential of afatinib in the treatment of patients with HER2-positive breast cancer. Breast Cancer (Dove Med Press) 2012;4:131-7.

78. Paplomata E, O'Regan R. The PI3K/AKT/mTOR pathway in breast cancer: Targets, trials, and biomarkers. Ther Adv Med Oncol 2014;6:154-66.

79. Verret B, Cortes J, Bachelot T, Andre F, Arnedos M. Efficacy of PI3K inhibitors in advanced breast cancer. Ann Oncol 2019;30:x12-20.

80. Schmid P, Pinder SE, Wheatley D, Macaskill J, Zammit C, Hu J, et al. Phase II randomized preoperative window-of-opportunity study of the pi3k inhibitor pictilisib plus anastrozole compared with anastrozole alone in patients with estrogen receptor-positive breast cancer. J Clin Oncol 2016:34:1987-94

81. Wolff AC, Lazar AA, Bondarenko I, Garin AM, Brincat S, Chow L, et al. Randomized phase III placebo-controlled trial of letrozole plus oral temsirolimus as first-line endocrine therapy in postmenopausal women with locally advanced or metastatic breast cancer. J Clin Oncol 2013;31:195-202.

82. Sabnis GJ, Goloubeva O, Chumsri S, Nguyen N, Sukumar S, Brodie AM. Functional activation of the estrogen receptor- $\alpha$ and aromatase by the HDAC inhibitor entinostat sensitizes ER-negative tumors to letrozole. Cancer Res 2011;71:1893-903.

83. Rižner TL. The important roles of steroid sulfatase and sulfotransferases in gynecological diseases. Front Pharmacol 2016;7:30.

84. Rasmussen LM, Zaveri NT, Stenvang J, Peters RH, Lykkesfeldt AE. A novel dual-target steroid sulfatase inhibitor and antiestrogen: SR 16157, a promising agent for the therapy of breast cancer. Breast Cancer Res Treat 2007;106:191-203.

85. Rosenberg JE, Hoffman-Censits J, Powles T, van der Heijden MS, 
Balar AV, Necchi A, et al. Atezolizumab in patients with locally advanced and metastatic urothelial carcinoma who have progressed following treatment with platinum-based chemotherapy: A single-arm, multicentre, phase 2 trial. Lancet 2016;387:1909-20.

86. Motzer RJ, Escudier B, McDermott DF, George S, Hammers HJ, Srinivas $\mathrm{S}$, et al. Nivolumab versus everolimus in advanced renal-cell carcinoma. N Engl J Med 2015;373:1803-13.

87. Robert C, Schachter J, Long GV, Arance A, Grob JJ, Mortier L, et al. Pembrolizumab versus ipilimumab in advanced melanoma. N Engl J Med 2015;372: 2521-32.

88. Muro K, Chung HC, Shankaran V, Geva R, Catenacci D, Gupta S, et al. Pembrolizumab for patients with PD-L1-positive advanced gastric cancer (KEYNOTE-012): A multicentre, open-label, phase $1 \mathrm{~b}$ trial. Lancet Oncol 2016;17:717-26.

89. Brahmer J, Reckamp KL, Baas P, Crinò L, Eberhardt WE, Poddubskaya E, et al. Nivolumab versus docetaxel in advanced squamous-cell non-smallcell lung cancer. N Engl J Med 2015;373:123-35.

90. Jeffrey S, Hodi FS, Wolchok JD, Topalian SL, Schadendorf D, Larkin J, et al. Safety profile of nivolumab (NIVO) in patients (pts) with advanced melanoma (MEL): A pooled analysis. J Clin Oncol 2015;33:9018.

91. Kaufman HL, Russell J, Hamid O, Bhatia S, Terheyden P, D'Angelo SP, et al. Avelumab in patients with chemotherapy-refractory metastatic Merkel cell carcinoma: A multicentre, single-group, open-label, phase 2 trial. Lancet Oncol 2016;17:1374-85.

92. Boyerinas B, Jochems C, Fantini M, Heery CR, Gulley JL, Tsang KY, et al. Antibody-dependent cellular cytotoxicity activity of a novel antipd-11 antibody avelumab (MSB0010718C) on human tumor cells. Cancer Immunol Res 2015;3:1148-57.

93. Collins JM, Gulley JL. Product review: Avelumab, an anti-PD-L1 antibody. Hum Vaccin Immunother 2019;15:891-908.

94. Dawicki-McKenna JM, Langelier MF, DeNizio JE, Riccio AA, Cao CD, Karch KR, et al. PARP-1 activation requires local unfolding of an autoinhibitory domain. Mol Cell 2015;60:755-68.

95. Ossovskaya V, Lim C, Schools G, et al. The Chemosensitizing Properties Ofiniparib in Combination with DNA-Damaging Agents in the MDA-MB-468(-) Triple-Negative Breast Cancer (TNBC) Cell Line. Orlando, FL: Proceedings of the American Association for Cancer Research; 2011.

96. Crown J, O'Shaughnessy J, Gullo G. Emerging targeted therapies in triple-negative breast cancer. Ann Oncol 2012;23:vi56-65.

97. Osborne CK, Wakeling A, Nicholson RI. Fulvestrant: An oestrogen receptor antagonist with a novel mechanism of action. Br J Cancer 2004;90:S2-6.

98. Wardley AM. Fulvestrant: A review of its development, pre-clinical and clinical data. Int J Clin Pract 2002;56:305-9.

99. Peddi PF, Hurvitz SA. Trastuzumab emtansine: The first targeted chemotherapy for treatment of breast cancer. Future Oncol 2013;9:319-26.

100. Boyraz B, Sendur MA, Aksoy S, Babacan T, Roach EC, Kizilarslanoglu MC, et al. Trastuzumab emtansine (T-DM1) for HER2-positive breast cancer. Curr Med Res Opin 2013;29:405-14.

101. Linderholm BK, Hellborg H, Johansson U, Elmberger G, Skoog L, Lehtiö J, et al. Significantly higher levels of vascular endothelial growth factor (VEGF) and shorter survival times for patients with primary operable triple-negative breast cancer. Ann Oncol 2009;20:1639-46.

102. Tomao F, Papa A, Zaccarelli E, Rossi L, Caruso D, Minozzi M, et al. Triple-negative breast cancer: New perspectives for targeted therapies. Onco Targets Ther 2015;8:177-93.

103. Yardley DA, Weaver R, Melisko ME, Saleh MN, Arena FP, Forero A, et al. EMERGE: A randomized phase II study of the antibody-drug conjugate glembatumumab vedotin in advanced glycoprotein NMBexpressing breast cancer. J Clin Oncol 2015;33:1609-19.

104. Adams S, Schmid P, Rugo HS, Winer EP, Loirat D, Awada A, et al. Pembrolizumab monotherapy for previously treated metastatic triplenegative breast cancer: Cohort A of the phase II KEYNOTE-086 study. Ann Oncol 2019;30:397-404.

105. Desai N, Trieu V, Yao Z, Louie L, Ci S, Yang A, et al. Increased antitumor activity, intratumor paclitaxel concentrations, and endothelial cell transport of cremophor-free, albumin-bound paclitaxel, ABI-007, compared with cremophor-based paclitaxel. Clin Cancer Res
2006;12:1317-24

106. Yoshida T, Ozawa Y, Kimura T, Sato Y, Kuznetsov G, Xu S, et al. Eribulin mesilate suppresses experimental metastasis of breast cancer cells by reversing phenotype from epithelial-mesenchymal transition (EMT) to mesenchymal-epithelial transition (MET) states. Br J Cancer 2014;110:1497-505.

107. Funahashi Y, Okamoto K, Adachi Y, Semba T, Uesugi M, Ozawa Y, et al. Eribulin mesylate reduces tumor microenvironment abnormality by vascular remodeling in preclinical human breast cancer models. Cancer Sci 2014;105:1334-42.

108. Zhang P, Sun T, Zhang Q, Yuan Z, Jiang Z, Wang XJ, et al. Utidelone plus capecitabine versus capecitabine alone for heavily pretreated metastatic breast cancer refractory to anthracyclines and taxanes: A multicentre, open-label, superiority, phase 3, randomized controlled trial. Lancet Oncol 2017;18:371-83.

109. Weledji EP, Tambe J. Breast cancer detection and screening. Med Clin Rev 2018;4:1-8.

110. Li H, Zhang S, Wang Q, Zhu R. Clinical value of mammography in diagnosis and identification of breast mass. Pak J Med Sci 2016;32:1020-5

111. Nounou MI, ElAmrawy F, Ahmed N, Abdelraouf K, Goda S, SyedSha-Qhatta H. Breast cancer: Conventional diagnosis and treatment modalities and recent patents and technologies. Breast Cancer (Auckl) 2015;9:17-34

112. McDonald ES, Clark AS, Tchou J, Zhang P, Freedman GM. Clinical diagnosis and management of breast cancer. J Nucl Med 2016;57: 9S-16.

113. Jourquin J, Reffey SB, Jernigan C, Jernigan C, Levy M, Zinser G, et al. Susan G. Komen big data for breast cancer initiative: How patient advocacy organizations can facilitate using big data to improve patient outcomes. JCO Precis Oncol 2019;3:PO.19.00184.

114. Smoot B, Wampler MA, Topp K. Breast cancer treatments and complications: Implications for rehabilitation. Rehabil Oncol 2009;27:16-26

115. Dang CC, Amiruddin M, Lai SS, Low CF. An emerging role of pharmacist in pre-chemotherapy counselling among breast cancer patients. Indian J Pharm Sci 2017;79:294-302.

116. Alvarez RH, Valero V, Hortobagyi GN. Emerging targeted therapies for breast cancer. J Clin Oncol 2010;28: 3366-79.

117. Osborne C, Wilson P, Tripathy D. Oncogenes and tumor suppressor genes in breast cancer: Potential diagnostic and therapeutic applications. Oncologist 2004;9:361-77.

118. Disis ML, Park KH. Immunomodulation of breast cancer via tumor antigen-specific Th1. Cancer Res Treat 2009;41:117-21.

119. Weber G, Chamorro CI, Granath F, Liljegren A, Zreika S, Saidak Z, et al. Human antimicrobial protein hCAP18/LL-37 promotes a metastatic phenotype in breast cancer. Breast Cancer Res 2009;11:R6.

120. Kelemen L, Couch FJ, Ahmed S, Dunning AM, Pharoah PD, Easton DF, et al. Genetic variation in stromal proteins decorin and lumican with breast cancer: Investigations in two case-control studies. Breast Cancer Res 2008;10:R98.

121. Borgquist S, Jögi A, Pontén F, Rydén L, Brennan DJ, Jirström K. Prognostic impact of tumor-specific HMG-CoA reductase expression in primary breast cancer. Breast Cancer Res 2008;10:R79.

122. PDQ Adult Treatment Editorial Board. Breast Cancer Treatment and Pregnancy $\left(\mathrm{PDQ}^{\circledR}\right) ; 2014$.

123. Amjad A, Khan II, Kausar Z, Saeed F, Azhar L, Anwar P. Risk factors in breast cancer progression and current advances in therapeutic approaches to knockdown breast cancer. Clin Med Biochem 2018;4:1.

124. Lana Burgess. Tumor Size Relates to the Breast Cancer Stage; 2019. Available from: https://www.medicalnewstoday.com/articles/325669.

125. Sign and Symptoms of Breast Cancer. MedLux International Hospital; 2020. Available from: https://www.medluxinternational.com/breastcancer/signs-and-symptoms-of-breast-cancer.

126. Potential treatment Options after a Breast Cancer Diagnosis; 2020. Available from: https:/www.yoursun.com/coastal/health/potentialtreatment-options-after-a-breast-cancer-diagnosis/article_d0e8bd8afdcd-11ea-aa3c-0bfc732ae62d.html. 